\title{
Experimental and Simulation Study of Adsorption in Postcombustion Conditions Using a Microporous Biochar. 1. $\mathrm{CO}_{2}$ and $\mathrm{N}_{2}$ Adsorption
}

\author{
Marta G. Plaza, Inés Durán, Nausika Querejeta, Fernando Rubiera, and Covadonga Pevida* \\ Instituto Nacional del Carbón, INCAR-CSIC, Apartado 73, 33080 Oviedo, Spain
}

Supporting Information

ABSTRACT: The influence of $\mathrm{N}_{2}$ on $\mathrm{CO}_{2}$ adsorption was evaluated using a microporous biochar with a narrow pore size distribution. The adsorption isotherms of pure $\mathrm{CO}_{2}$ and $\mathrm{N}_{2}$ were measured at $0,30,50$, and $70{ }^{\circ} \mathrm{C}$ up to $120 \mathrm{kPa}$ and fitted to the Toth adsorption model. Dynamic breakthrough experiments were carried out in a fixed-bed adsorption unit using binary mixtures with compositions representative of different postcombustion streams $\left(8-30 \% \mathrm{CO}_{2}\right)$ from ambient temperature to $70{ }^{\circ} \mathrm{C}$. Dynamic adsorption experiments were simulated to validate the mathematical model of the adsorption process, as a necessary step for its later use for process design. The Ideal Adsorption Solution (IAS) theory, based on the pure component adsorption models, was used to account for competitive adsorption with satisfactory results. The information gathered in the present work will be used to extend the validity of the model to the adsorption of postcombustion streams containing $\mathrm{H}_{2} \mathrm{O}$ in part 2 .

\section{INTRODUCTION}

In the postcombustion $\mathrm{CO}_{2}$ capture scenario, where $\mathrm{CO}_{2}$ is to be separated from the flue gas arising from fossil fuel combustion, the gas stream that needs to be decarbonized is mainly composed of $\mathrm{N}_{2}, \mathrm{O}_{2}, \mathrm{CO}_{2}$, and $\mathrm{H}_{2} \mathrm{O}$ with much lesser contents of $\mathrm{NO}_{x}$ and $\mathrm{SO}_{x}$. Chemical separation processes with liquid solvents are based on the reaction of the $\mathrm{CO}_{2}$ with an amine solution in the absorber, where a decarbonized flue gas is produced. The spent amine is sent to the stripper, where the solvent is heated by means of steam, releasing the $\mathrm{CO}_{2}$ and providing lean amine to the absorber on a continuous basis. Separation processes based on adsorption aim to reduce the energy penalty of the capture process by eliminating the need of heating a vast amount of water (up to $70 \%$ by weight of the solvent). However, the primary requirement to develop an economic adsorption-based separation process is to find an adsorbent with high selectivity, availability, capacity, life, and low cost. ${ }^{1}$ Availability, stability, and low cost are the main advantages of biomass-based carbon adsorbents. The requirement of adequate adsorptive capacity toward $\mathrm{CO}_{2}$ under postcombustion conditions (low partial pressure of $\mathrm{CO}_{2} \approx 15$ $\mathrm{kPa}$ ) and temperatures in the nearby region of $50{ }^{\circ} \mathrm{C}$, restrict the choice to microporous adsorbents with a narrow pore size distribution. ${ }^{1-7}$ These can be developed from biomass residues by controlled activation conditions. ${ }^{8-12}$ The selectivity in adsorption-based separation processes may arise from a difference in adsorption kinetics or, more frequently, from the equilibrium of adsorption. ${ }^{1}$ Microporous carbons present equilibrium selectivity toward $\mathrm{CO}_{2}$ over $\mathrm{N}_{2}$, which is the major flue gas component, due to the higher quadrupole moment of the $\mathrm{CO}_{2}$ molecule compared to that of $\mathrm{N}_{2} \cdot \mathrm{O}_{2}$ presents similar

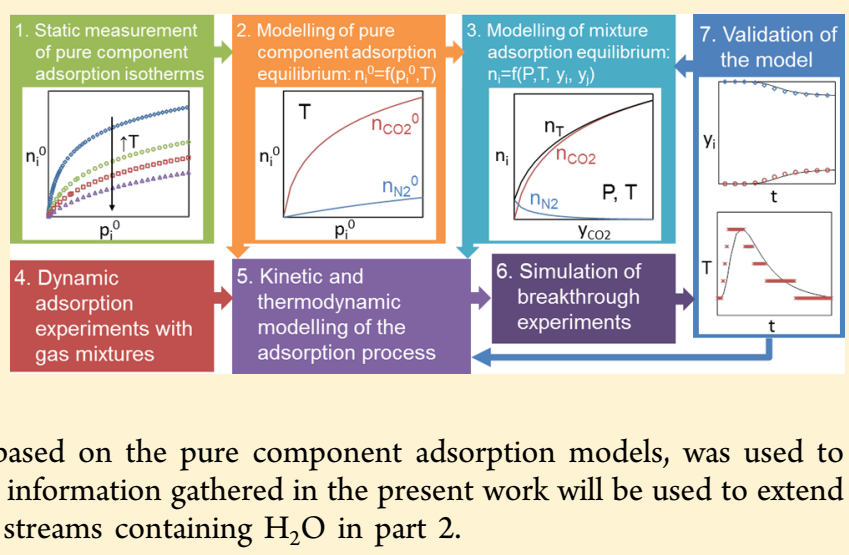

equilibrium adsorption capacity than $\mathrm{N}_{2}$. The trace amounts of $\mathrm{SO}_{x}$ and $\mathrm{NO}_{x}$ present in flue gas are not expected to be a problem for physical adsorbents, although they can deactivate amines in reaction-based separation processes. ${ }^{13}$ The effect of $\mathrm{H}_{2} \mathrm{O}$, which has a permanent dipole, needs special attention and will be the focus of part 2 of the present work. The impact of competitive adsorption is frequently dismissed, and adsorbent selection and process design are sometimes based solely on the adsorption models of pure components, which can lead to erroneous conclusions. The use of the pure component adsorption models, although it is simple and convenient, assumes that the adsorbates adsorb independently of each other, which is physically impossible due to the limited pore volume available. On the other hand, multicomponent adsorption equilibrium models account for the competition between the adsorbates present in the gas phase. The partition of the adsorption sites is not expected to be symmetrical for every component in the gas phase, as the affinity of the surface for different adsorbate molecules differs greatly. The collection of equilibrium data for multicomponent adsorption is tedious and subject to greater experimental error than those of pure component adsorption measurements. Therefore, multicomponent adsorption models are frequently based on pure component adsorption models that predict accurately the behavior of the equilibrium of adsorption of the pure components in a wide range of operating conditions. One of

Received: December 19, 2015

Revised: February 17, 2016

Accepted: February 25, 2016

Published: February 25, 2016 
the available options is to use the Ideal Adsorption Solution (IAS) theory. ${ }^{14}$ The main advantage of IAS is that it is based on the solution thermodynamics and thus it is independent of the actual model of adsorption, allowing the use of different adsorption models for different adsorbates. This is particularly important in the case of $\mathrm{H}_{2} \mathrm{O}$ adsorption on carbon materials, which follows a completely different adsorption mechanism than that of $\mathrm{CO}_{2}$ and $\mathrm{N}_{2}$. In this work, the competition between $\mathrm{CO}_{2}$ and $\mathrm{N}_{2}$ adsorption under postcombustion capture conditions on a microporous biochar was evaluated making use of IAS, as a previous step to assess the influence of $\mathrm{H}_{2} \mathrm{O}$.

The equilibrium of adsorption of pure $\mathrm{CO}_{2}$ and $\mathrm{N}_{2}$ was evaluated using a static manometric apparatus in a temperature range of interest for postcombustion $\mathrm{CO}_{2}$ capture: between 0 and $70{ }^{\circ} \mathrm{C}$ and up to $120 \mathrm{kPa}$. The equilibrium data for the adsorption of pure $\mathrm{CO}_{2}$ and $\mathrm{N}_{2}$ were fitted to the temperature dependent Toth adsorption model, as it provides a satisfactory description of the experimental data and has the correct behavior in the low and high pressure range. The use of mathematical expressions to describe the equilibrium of adsorption of the pure components provides a convenient way to predict the adsorption behavior at intermediate temperatures and pressures in a continuous form, thus allowing the implementation of the equilibrium model in the full mathematical model that describes the separation process, and which is very useful for process design purposes. Although the equilibrium of adsorption could be directly assessed from breakthrough measurements in a fixed-bed adsorption unit, these are subjected to greater experimental error than those from static manometric devices (small absolute errors in the flow rate measurement can lead to large relative errors in the cumulative amount adsorbed, especially for $\mathrm{N}_{2}$, due to the larger flow rate involved and the lower adsorption capacity). The automated static manometric adsorption apparatus provides a large number of equilibrium data with higher accuracy in lesser experimental time. It must be borne in mind that the success of the calculation of IAS strongly depends on the quality of the single component adsorption data and on the goodness of the fitting, especially in the low and high pressure ranges. ${ }^{15}$ On the other hand, dynamic measurements carried out with multicomponent mixtures in a fixed-bed adsorption unit allow assessment of the effect of competitive adsorption, and also evaluation of the kinetics of adsorption, which will have a significant impact on the process design. Therefore, the information given by static and dynamic adsorption techniques is complementary. Moreover, it is very useful to couple the information obtained by different techniques, since this provides an extra validation of the results.

The adsorption of binary mixtures of $\mathrm{CO}_{2}$ and $\mathrm{N}_{2}$ with composition between 8 and $30 \%$ of $\mathrm{CO}_{2}$ which can be considered representative of different postcombustion streams, ${ }^{16}$ such as that produced by a natural gas boiler ( $8 \%$ $\left.\mathrm{CO}_{2}\right)$, by a pulverized coal fired boiler $\left(14 \% \mathrm{CO}_{2}\right)$, or by a cement plant $\left(30 \% \mathrm{CO}_{2}\right)$, was assessed through breakthrough studies carried out in a fixed-bed adsorption unit. The effect of the temperature of adsorption was also assessed by running breakthrough curves of a postcombustion mixture with $14 \%$ $\mathrm{CO}_{2}$ (balance $\mathrm{N}_{2}$ ) in a wide temperature range, from room temperature to $70{ }^{\circ} \mathrm{C}$. These results were used to validate the mathematical model of the adsorption process. Experimental validation of the model is a crucial step in order to gain confidence on the simulation results before using the model for the design of the adsorption-based $\mathrm{CO}_{2}$ capture process and should never be neglected.

\section{MATERIALS AND METHODS}

Adsorbent. The adsorbent used in the present work is a microporous biochar obtained from olive stones by single-step oxidation. ${ }^{10}$ The adsorbent characteristics are summarized in Table 1. This is a Granular Activated Carbon (GAC) with a

Table 1. Adsorbent Characteristics

\begin{tabular}{ll}
\multicolumn{1}{c}{ particle size } & $1.0 \mathrm{~mm}<D_{\mathrm{p}}<3.3 \mathrm{~mm}$ \\
solid density & $1801 \mathrm{~kg} \mathrm{~m}^{-3}$ \\
particle density & $775 \mathrm{~kg} \mathrm{~m}^{-3}$ \\
bulk density & $455 \mathrm{~kg} \mathrm{~m}^{-3}$ \\
specific heat capacity & $0.7457+0.0044 \cdot T\left({ }^{\circ} \mathrm{C}\right) \mathrm{J} \mathrm{g}^{-1}{ }^{\circ} \mathrm{C}^{-1}$ \\
textural characterization & \\
$S_{\mathrm{BET}}\left(\mathrm{m}^{2} \mathrm{~g}^{-1}\right)$ & 415 \\
$W_{\mathrm{DR}, \mathrm{CO}_{2}}\left(\mathrm{~cm}^{3} \mathrm{~g}^{-1}\right)$ & 0.24 \\
$L_{0, \mathrm{CO}_{2}}(\mathrm{~nm})$ & 0.56 \\
elemental analysis (wt \%, dry ash free basis $)$ \\
$\mathrm{C}$ & 90.7 \\
$\mathrm{H}$ & 1.4 \\
$\mathrm{~N}$ & 0.5 \\
$\mathrm{O}$ & 7.4 \\
\hline
\end{tabular}

particle size between 1.0 and $3.3 \mathrm{~mm}$. The bulk density shown in Table 1 is the packing density of the adsorbent in the fixedbed adsorber column, which was carefully filled to keep the interparticle void volume to the minimum. The bulk density of this material is relatively large for GAC, ${ }^{11}$ which is interesting from the application point of view, as it will reduce the volume of the adsorber required. Table 1 also presents the apparent density, determined by mercury intrusion at $0.1 \mathrm{MPa}$ in an Autopore IV 9500, from Micromeritics, and the solid density, determined by helium pycnometry at $35{ }^{\circ} \mathrm{C}$ in an AccuPyC 1330 from Micromeritics. The apparent density of the biochar evaluated in this work is large compared to other GAC developed from the same precursor by $\mathrm{CO}_{2}$ activation due to the narrower pore size distribution of the biochar., ${ }^{9,17}$ The porous texture was characterized by physical adsorption of $\mathrm{N}_{2}$ at $-196{ }^{\circ} \mathrm{C}$ in an ASAP 2010 from Micromeritics, and by $\mathrm{CO}_{2}$ adsorption at $0{ }^{\circ} \mathrm{C}$ in a TriStar 3000 from Micromeritics. The $\mathrm{N}_{2}$ adsorption isotherm at $-196{ }^{\circ} \mathrm{C}$ can be found in the Supporting Information. The BET surface area $\left(S_{\mathrm{BET}}\right)$, calculated from the adsorption isotherm of $\mathrm{N}_{2}$ at $-196{ }^{\circ} \mathrm{C}$, is shown in Table 1 . The value of $S_{\mathrm{BET}}$ is moderate, because the activation conditions were optimized to obtain a strictly microporous carbon with a narrow pore size distribution, ${ }^{10}$ which is of the utmost importance for the adsorption of $\mathrm{CO}_{2}$ at low pressures. ${ }^{4-8,10,18}$ Microporous carbonaceous adsorbents obtained by moderate activation possess a rather narrow poresize distribution that can be considered to be practically homogeneous with structures close to carbon molecular sieves. ${ }^{19}$ The volume of ultramicropores, determined from the adsorption isotherm of $\mathrm{CO}_{2}$ at $0{ }^{\circ} \mathrm{C}$ using the DubininRaduskevitch method ${ }^{20}\left(W_{\mathrm{DR}, \mathrm{CO}_{2}}\right)$, is shown in Table 1 together with the average width of the micropore system $\left(L_{0}\right)$ calculated using the Stoeckli-Ballerini relation. ${ }^{21}$ The DR method applies over a wide range of relative pressures, as expected for adsorbents with homogeneous micropore structures. $^{19}$ 
The elemental analysis of the adsorbent, carried out by a LECO CHN-2000 and a LECO VTF-900, is also shown in Table 1 . The biochar is mainly composed by carbon with much lesser amounts of oxygen, hydrogen, and nitrogen.

The specific heat capacity of the biochar was determined in a C80 Calvet Calorimeter from Setaram using a heating rate of $0.2{ }^{\circ} \mathrm{C} \mathrm{min}-1$. Two replica experiments were performed with a standard deviation equal to or lower than 0.02 . The specific heat capacity showed a linear temperature dependence between 40 and $100{ }^{\circ} \mathrm{C}$ (equation shown in Table 1 ).

Pure Component Equilibrium Measurements in Static Conditions. The adsorption isotherms of pure $\mathrm{CO}_{2}$ and $\mathrm{N}_{2}$ were measured at $0,30,50$, and $70{ }^{\circ} \mathrm{C}$ up to $120 \mathrm{kPa}$ using a commercial adsorption apparatus (TriStar 3000 from Micromeritics). Prior to the adsorption measurements, the sample was outgassed overnight under a vacuum at $100{ }^{\circ} \mathrm{C}$. During analysis, the temperature of the sample cell was controlled using a thermostatic bath circulator from Thermo Haake.

In a previous work, it was shown that the Toth adsorption model (eq 1) described satisfactorily the equilibrium of adsorption of pure $\mathrm{CO}_{2}$ and $\mathrm{N}_{2}$ at 0,25 , and $50{ }^{\circ} \mathrm{C}$ on a likewise biochar. ${ }^{10}$ In this work, the range of study has been extended to cover a wider range of temperatures that could be easily encountered in a postcombustion unit (under a vacuum swing and/or temperature swing operation, for example).

$$
n_{k}=n_{\mathrm{s}, k} \frac{b_{k} P_{k}}{\left(1+\left(b_{k} P_{k}\right)^{\tau_{k}}\right)^{1 / \tau_{k}}}
$$

In eq $1, n_{k}$ represents the adsorbed concentration of component $k$ (moles of $k$ adsorbed per mass of adsorbent), $n_{\mathrm{s}, k}$ is the saturation capacity of component $k, P_{k}$ is the partial pressure of component $k$ in the gas phase, $b_{k}$ is the affinity constant of component $k$, and $\tau_{k}$ is the heterogeneity parameter of component $k\left(\tau_{k} \leq 1\right)$. The temperature dependence of the model is given by eq $2:{ }^{15}$

$$
b_{k}=b_{0, k} \exp \left[\frac{Q_{k}}{R T_{0}}\left(\frac{T_{0}}{T}-1\right)\right]
$$

where $b_{0, k}$ is the affinity constant of component $k$ at a reference temperature $T_{0}$ (here taken as $273.15 \mathrm{~K}$ ), $Q_{k}$ is a measure of the heat of adsorption of component $k, T$ is the evaluated temperature, and $R$ is the universal constant of gases. The heterogeneity parameter $\tau_{k}$ was assumed to be constant with temperature. The parameters $n_{\mathrm{s}, k}, b_{0, k}, Q_{k}$, and $\tau_{k}$ were optimized by a nonlinear procedure to give the best fit to the experimental adsorption isotherms of pure $\mathrm{CO}_{2}$ and $\mathrm{N}_{2}$, taking the minimum of the Mean Squared Error (MSE) as the objective function (eq 3). The so optimized parameters for the adsorption of pure $\mathrm{CO}_{2}$ and $\mathrm{N}_{2}$ on the evaluated biochar are presented in Table 2.

$$
\operatorname{MSE}=\frac{\sum_{T}\left(\frac{\sum_{i=1}^{N_{\mathrm{A}}}\left(n_{\text {exp }}-n_{\text {call }}\right)^{2}}{N_{\mathrm{A}}}\right) \times 100}{N_{\mathrm{T}}}
$$

where $n_{\exp }$ represents the adsorbed concentration at a pressure $P$ and a temperature $T$ measured experimentally, $n_{\text {calc }}$ is the adsorbed concentration calculated at the same pressure and temperature using the adsorption model, $N_{\mathrm{T}}$ is the number of temperatures evaluated, and $N_{\mathrm{A}}$ is the number of adsorption points measured at each temperature.
Table 2. Optimal Parameters for the Toth Adsorption Model for the Adsorption of Pure $\mathrm{CO}_{2}$ and $\mathrm{N}_{2}$ on the Evaluated Biochar

\begin{tabular}{lcc} 
& $\mathrm{CO}_{2}$ & $\mathrm{~N}_{2}$ \\
$n_{\mathrm{m}}\left(\mathrm{mmol} \mathrm{g}^{-1}\right)$ & 5.6144 & 1.4331 \\
$b_{0}\left(\mathrm{kPa}^{-1}\right)$ & 0.1292 & 0.0054 \\
$\tau$ & 0.4343 & 0.9892 \\
$Q\left(\mathrm{~J} \mathrm{~mol}^{-1}\right)$ & 28916 & 18669 \\
$\mathrm{MSE}$ & 0.03 & 0.0006 \\
\hline
\end{tabular}

The isosteric heat of adsorption of $\mathrm{CO}_{2}$ and $\mathrm{N}_{2}$ was estimated from the pure component adsorption isotherms making use of the Clausius-Clapeyron equation. The plot of $(\ln P)$ against $(1 / T)$ at constant loading $(n)$ yields a straight line, the slope of which is equal to

$$
\left(-\frac{Q_{\mathrm{st}}}{R}\right)
$$

where $Q_{s t}$ is the isosteric heat of adsorption at the selected loading $n$.

Dynamic Adsorption Experiments with Binary Gas Mixtures. Dynamic experiments were carried out in a fixedbed adsorption unit using binary gas mixtures with three different compositions that can be considered representative of different postcombustion streams, 8,14 , and $30 \% \mathrm{CO}_{2}$ (balance $\mathrm{N}_{2}$ ), and at temperatures that could be encountered in a postcombustion scenario: room temperature $\left(23-25{ }^{\circ} \mathrm{C}\right), 50$ ${ }^{\circ} \mathrm{C}$, and $70{ }^{\circ} \mathrm{C}$. In all cases, the feed flow rate was set to $140 \mathrm{~cm}^{3}$ $\mathrm{min}^{-1}$ (volumetric flow rate given at Standard Pressure and Temperature conditions, STP: $0{ }^{\circ} \mathrm{C}$ and $0.1 \mathrm{MPa}$ ), the total pressure was $140 \mathrm{kPa}$, and the adsorbent was initially regenerated and in equilibrium with $\mathrm{N}_{2}$ at the experimental temperature. The adsorbent was regenerated between consecutive runs by heating the adsorber at $150{ }^{\circ} \mathrm{C}$ in $\mathrm{N}_{2}$ flow for at least $1 \mathrm{~h}$. Table 3 summarizes the experimental conditions of the experiments carried out. Cases 1, 2, and 3 were carried out at room temperature, monitoring the adsorbent temperature by means of a K-type thermocouple placed in the bulk of the bed at $4.7 \mathrm{~cm}$ from the feed end, but without temperature control. On the other hand, cases 4 and 5 were carried out under isothermal conditions $\left(\Delta T \leq \pm 2{ }^{\circ} \mathrm{C}\right)$ at 50 and $70{ }^{\circ} \mathrm{C}$, respectively, by automatically actuating a $700 \mathrm{~W}$ resistance coiled around the adsorber.

The fixed-bed adsorption unit used in this work is an improved version of that used in previous investigations for the evaluation of the adsorptive separation of $\mathrm{CO}_{2}$ from humid streams representative of postcombustion conditions. ${ }^{17,22,23}$ The original pressure transmitter, which had a working pressure range of $0-40 \mathrm{bar}$, was substituted by a pressure transmitter of 0-2.5 bar (WIKA, model A-10) to gain accuracy in the pressure range that is to be encountered in postcombustion conditions (accuracy $\leq \pm 1 \%$ of span). The Extra-Column Volume (ECV) of the adsorption unit has been reduced by replacing the original humidity probe housing (a high efficiency coalescing filter $360 \mathrm{~A}$, from Headline Filters) that presented a volume of $165 \mathrm{~cm}^{3}$ by a $1 / 2^{\prime \prime}$ tee adaptor with a volume of ca. 7 $\mathrm{cm}^{3}$. The largest contributor to the total ECV is now the desiccant column situated in the effluent line, just before the micro Gas Chromatograph ( $\mu \mathrm{GC})$. However, this element is necessary in order to protect the molecular sieve column of the $\mu \mathrm{GC}$ during humid operation (that will be discussed in part 2 of the present study). The dryer consists of a glass column with 
Table 3. Experimental Conditions of the Dynamic Experiments Carried out in the Fixed-Bed Adsorption Unit and Values of the Mass and Heat Transfer Coefficients Used to Run the Simulations

\begin{tabular}{|c|c|c|c|c|c|c|c|c|c|}
\hline \multirow[b]{2}{*}{ case } & \multirow[b]{2}{*}{ feed flow rate $\left(\mathrm{cm}^{3} \mathrm{~min}^{-1}, \mathrm{STP}\right)$} & \multicolumn{2}{|c|}{$\begin{array}{c}\text { feed } \\
\text { composition } \\
\text { (vol \%) }\end{array}$} & \multirow[b]{2}{*}{$T_{\mathrm{b}}\left({ }^{\circ} \mathrm{C}\right)$} & \multirow[b]{2}{*}{$P(\mathrm{kPa})$} & \multirow[b]{2}{*}{$D_{\mathrm{e}, \mathrm{CO}_{2}}\left(\mathrm{~m}^{2} \mathrm{~s}^{-1}\right)$} & \multirow[b]{2}{*}{ 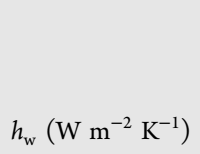 } & \multirow[b]{2}{*}{$\operatorname{HTC}\left(\mathrm{W} \mathrm{m}^{-2} \mathrm{~K}^{-1}\right)$} & \multirow[b]{2}{*}{$H_{\mathrm{amb}}\left(\mathrm{W} \mathrm{m} \mathrm{m}^{-2} \mathrm{~K}^{-1}\right)$} \\
\hline & & $\mathrm{N}_{2}$ & $\mathrm{CO}_{2}$ & & & & & & \\
\hline 1 & 140 & 92 & 8 & $25^{a}$ & 140 & $3 \times 10^{-9}$ & 36 & 45 & 6 \\
\hline 2 & 140 & 86 & 14 & $23^{a}$ & 140 & $3 \times 10^{-9}$ & 35 & 44 & 6 \\
\hline 3 & 140 & 70 & 30 & $25^{a}$ & 140 & $3 \times 10^{-9}$ & 33 & 43 & 6 \\
\hline 4 & 140 & 86 & 14 & 50 & 140 & $9 \times 10^{-9}$ & & & \\
\hline 5 & 140 & 86 & 14 & 70 & 140 & $2 \times 10^{-8}$ & & & \\
\hline
\end{tabular}

${ }^{a_{T}}$ The temperature in the adsorber was not controlled during this experiment $\left(T_{\mathrm{b}}=T_{\mathrm{amb}}\right.$ at $\left.t=0\right)$

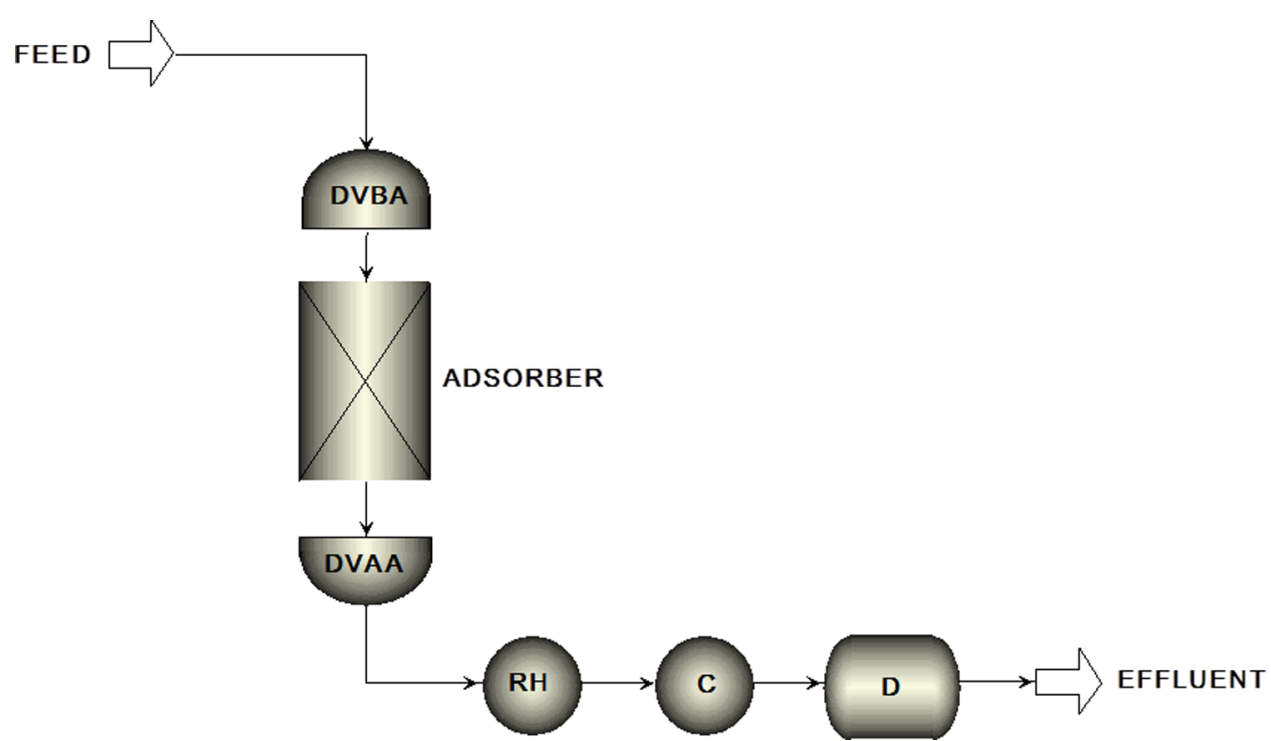

Figure 1. Flowsheet configuration used to run the simulations of the experimental breakthrough curves using Aspen Adsorption V8.0. DVBA, DVAA, RH, C, and D are gas_tank_void models that represent the extra-column volume of the fixed-bed adsorption unit.

a total empty volume of ca. $25 \mathrm{~cm}^{3}$ filled with magnesium perchlorate (ca. $9 \mathrm{~g}$ ). The rest of the ECV consists of $1 / 8^{\prime \prime}$ stainless steel tubing, fittings, and valves. The length of the tubing has also been reduced to the minimum. The original adsorber has been replaced by a stainless steel (SS316L) column with greater volume (internal diameter, $13 \mathrm{~mm}$; wall width, $3 \mathrm{~mm}$; adsorbent bed height, $11.7 \mathrm{~cm}$ ). After these modifications, the ratio of the adsorber volume to that of the ECV has been substantially improved. It was found important to reduce the ECV, as this contributes to the spread of the experimentally measured breakthrough curves. ${ }^{24}$ The transient response of the modified unit was evaluated by running blank experiments with the adsorber filled with glass beads with a diameter of $2 \mathrm{~mm}$, which is close to the average diameter of the biochar particles.

The cumulative amount of $\mathrm{CO}_{2}$ adsorbed at a given time $t$ $\left(n_{\mathrm{CO}_{2}, \text { exp, }, t}\right)$ was estimated from the experimental breakthrough curves by making a component mass balance to the unit and discounting the hold up in the gas phase (eq 4):

$$
\begin{aligned}
& n_{\mathrm{CO}_{2}, \text { exp }, t}-n_{\mathrm{CO}_{2}, \text { exp }, t=0} \\
& =\frac{\left(\int_{0}^{t} F_{\mathrm{in}, \mathrm{CO}_{2}} d \mathrm{t}-\int_{0}^{t} F_{\text {out }, \mathrm{CO}_{2}} d \mathrm{t}\right)-\left.\left(\frac{p_{\mathrm{CO}_{2}} \mathrm{ECV}}{R T_{\mathrm{amb}}}+\frac{{ }_{\mathrm{pO}_{2}} \varepsilon_{\mathrm{T}} V_{\mathrm{b}}}{R T_{\mathrm{b}}}\right)\right|_{t=0} ^{t}}{\text { mass of adsorbent }}
\end{aligned}
$$

where $F_{\mathrm{in}, \mathrm{CO}_{2}}$ and $F_{\text {out, } \mathrm{CO}_{2}}$ refer to the molar flow rate of $\mathrm{CO}_{2}$ entering and leaving the adsorber, respectively, $p_{\mathrm{CO}_{2}}$ is the partial pressure of $\mathrm{CO}_{2}$ in the gas phase, $T_{\mathrm{amb}}$ is the ambient temperature, $\mathrm{ECV}$ is the total extra column volume of the unit, $\varepsilon_{\mathrm{T}}$ is the total porosity of the adsorbent bed, $V_{\mathrm{b}}$ is the volume of the bed of adsorbent, and $T_{\mathrm{b}}$ is the adsorber temperature.

Simulation of Dynamic Adsorption Experiments. Breakthrough experiments were simulated using Aspen Adsorption V8.0 with the flowsheet configuration shown in Figure 1. The ECV was accounted for using a series of gas tank_void models that pretend to emulate the experimental setup: DVBA represents the dead volume before the adsorber (sum of the volume of tubing between the feed section and the adsorber and the void space inside the adsorber above the adsorbent bed: $\left.3.0 \mathrm{~cm}^{3}\right)$. DVAA represents the dead volume after the adsorber up to the bypass valve $\left(5.3 \mathrm{~cm}^{3}\right)$. $\mathrm{RH}$ represents the volume between the bypass valve and the relative humidity probe and the pressure transducer $\left(7.7 \mathrm{~cm}^{3}\right) . \mathrm{C}$ accounts for the volume between the pressure transducer and the coriolis mass flow meter $\left(2.1 \mathrm{~cm}^{3}\right)$, and $\mathrm{D}$ accounts for the void volume of the desiccant column $\left(22.6 \mathrm{~cm}^{3}\right)$. The block labeled Adsorber accounts for a gas_bed model that represents the adsorption column of the experimental unit. Aspen Adsorption uses a set of partial differential equations (PDEs), ordinary differential equations (ODEs) and algebraic equations, that represent the mass, momentum and energy balances, and 
the kinetic and the equilibrium models, together with the appropriate initial and boundary conditions, to fully describe the adsorption process (a summary of the model equations can be found in the Supporting Information). Spatial derivatives are discretized using algebraic approximations, resulting in a set of ordinary differential equations and algebraic equations (DAEs). The spatial derivatives for the adsorber bed model were discretized using the upwind differencing scheme 1 method (UDS1, first order), dividing the axial coordinate of the adsorber into 30 nodes. Further details of the simulation environment can be found elsewhere. ${ }^{25}$ The following assumptions were made: The adsorbent packing is uniform through the bed. Gas flow is described as plug flow with axial dispersion. The system is fully mixed in the radial direction. The nonideality of the gas phase is taken into consideration by means of the compressibility factor, which is calculated locally using Aspen's physical properties package. And, the local pressure and gas velocity are related by the Ergun equation. The axial dispersion coefficient was estimated locally for the superficial velocity of the gas phase (see Supporting Information for details).

In the gas phase adsorption process, several resistances to mass transfer occur in series: (i) resistance of the boundary layer of the particle to the mass transfer between the bulk gas and the gas-solid interface and (ii) intraparticle mass transfer resistance (diffusion in the pore system and surface diffusion). The kinetic submodel of the overall fixed-bed adsorption model represents the resistances to mass transfer. In this work, two kinetic models are compared: (i) a lumped resistance model based on a linear driving force (LDF) approximation in the solid phase where the separate mass transfer phenomena are lumped as a single overall factor (valid when one mass transfer resistance is rate-limiting) and (ii) a combined model that takes into consideration the mass transfer resistance in the boundary layer and the intraparticle mass transfer resistance in the adsorbed phase (Particle MB). The latter determines the local loading inside the adsorbent particle by solving numerically the mass balance at the particle level assuming spherical geometry, and using central finite difference discretization of the radial coordinate with 50 nodes. It is also assumed that the effective adsorbed phase diffusion coefficient is constant throughout the particle. The kinetic model equations can be found in the Supporting Information. The effective adsorbed phase diffusion coefficients $\left(D_{\mathrm{e}}\right)$ were fitted to reproduce the experimental data, as will be discussed in the Results section (the values of $D_{\mathrm{e}}$ used to run the simulations of cases 1-5 are shown in Table 3 ). The molecular diffusivities of the components in the gas mixture were calculated for the feed composition and the experiment temperature using the Wilke method ${ }^{26}$ and the Chapman-Enskog theory ${ }^{29}$ and were assumed to be approximately constant.

The gas, solid, and wall energy balances were solved for the experiments carried out without temperature control (cases 1, 2, and 3) making the following assumptions: The thermal conductivity of the biochar was estimated using the empirical correlation of Prakash et al. ${ }^{28}\left(k_{\mathrm{s}} \approx 0.128 \mathrm{~W} \mathrm{~m}^{-1} \mathrm{~K}^{-1}\right)$. The analogy between heat transfer and mass transfer is valid (the effective thermal conductivity of the gas phase is calculated locally using the axial dispersion coefficient; see Supporting Information for details). The heat capacity of the adsorbed phase was assumed to be equal to the gas phase (the isosteric heat of adsorption is assumed to be nearly temperature independent ${ }^{29}$ ). The heat of adsorption is considered constant and equal to that given by the Toth model. The heat transfer coefficient between the gas and the adsorbent particles (HTC) was calculated using the correlation of Wakao and Kaguei ${ }^{30}$ for the feed conditions and assumed to be approximately constant (the values of HTC used to run the simulations of cases 1, 2, and 3 are shown in Table 3). The heat transfer coefficient between the gas and the adsorber wall $\left(h_{\mathrm{w}}\right)$ was estimated using the correlation proposed by Yagi and Kunii for cylindrical packed beds ${ }^{31}$ for the feed conditions and assumed to be approximately constant (the values of $h_{\mathrm{w}}$ used to run the simulations of cases 1, 2, and 3 are shown in Table 3). The heat transfer coefficient between the outer wall of the adsorber and the environment $\left(H_{\mathrm{amb}}\right)$ was assumed approximately constant; the same value of $H_{\mathrm{amb}}$ was used to run the simulations of cases 1,2 , and 3 as shown in Table 3. This was set to a low value, typical for natural air convection: $6 \mathrm{~W} \mathrm{~m}^{-2} \mathrm{~K}^{-1}$ (the adsorber is not isolated from ambient air, and the laboratory is a closed room with low air circulation). The experiments carried out under temperature control (cases 4 and 5 , where $\Delta T \leq \pm 2$ $\left.{ }^{\circ} \mathrm{C}\right)$ were simulated assuming isothermal operation $\left(T_{\mathrm{g}}=T_{\mathrm{s}}=\right.$ $\left.T_{\mathrm{w}}\right)$.

The IAS theory ${ }^{14}$ was used to model the multicomponent adsorption equilibrium based on the pure component adsorption models (Toth). The equation set for IAS computation is given by ${ }^{15}$

$$
y_{k} P=x_{k} p_{k}^{0}(\pi)
$$

where $y_{k}$ refers to the mole fraction of component $k$ in the gas phase, $P$ is the pressure of the gas phase, $x_{k}$ refers to the mole fraction of component $k$ in the adsorbed phase, and $p_{k}^{0}$ is the hypothetical pressure of the pure component $k$ that gives the same spreading pressure $(\pi)$ on the surface as that of the mixture. Equation 5 is the analog Raoult's law for an ideal adsorption system: the activity coefficient for ideal solution is 1 , and the fugacity of the gas phase can be approximated by the partial pressure unless the pressure of the gas phase is very high. The mole fractions in the gas phase and the adsorbed phase must satisfy:

$$
\begin{aligned}
& \sum_{i=1}^{n c} x_{i}=1 \\
& \sum_{i=1}^{n c} y_{i}=1
\end{aligned}
$$

By defining a standard state in which the surface potential of the mixture $(\phi)$ is the same as the surface potential of all pure components $\left(\phi_{k}^{0}\right)$, we have

$$
\frac{\phi}{R T}=\frac{\phi_{k}^{0}}{R T}=-\int_{0}^{p_{k}^{0}} \frac{n_{k}^{0}}{P_{k}} \mathrm{~d} P_{k}
$$

where $n_{k}^{0}$ is the adsorbed concentration of pure component $k$ at the hypothetical pressure $p_{k}^{0}$ given by the pure component adsorption isotherm: $n_{k}^{0}=f^{0}\left(p_{k}^{0}\right)$. The spreading pressure is the negative of the surface potential. The reduced spreading pressure is defined by

$$
z=\frac{A \pi}{R T}=z_{k}=\frac{A \pi_{k}^{0}}{R T}=\int_{0}^{p_{k}^{0}} \frac{n_{k}^{0}}{P_{k}} \mathrm{~d} P_{k}
$$

where 


$$
\pi_{k}^{0}=\pi_{i}^{0}=\pi_{j}^{0}=\ldots=\pi_{n c}^{0}
$$

Solving numerically eqs $5,6,9$, and 10 , the total loading $\left(n_{\mathrm{T}}\right)$ is calculated from

$$
\sum_{i=1}^{n c} \frac{x_{i}}{n_{i}^{0}}=\frac{1}{n_{T}}
$$

Finally, knowing the total adsorbed concentration $\left(n_{\mathrm{T}}\right)$, the component loadings are calculated by

$$
n_{k}=x_{k} n_{\mathrm{T}}
$$

The computation of IAS theory is fully implemented in Aspen Adsorption for certain pure component adsorption isotherms: Langmuir, Freundlich, Sips, Henry, and BET. However, it is also possible to use the IAS theory with user specified adsorption isotherms. In order to do so, a user submodel, gUserIsothermPoi, was added to the flowsheet constraints of the simulation files to supply the pure component isotherm of each component $k$ as a function of the hypothetical pressure of the pure component that gives the same spreading pressure on the surface as that of the mixture: $n_{k}^{0}=f^{0}\left(p_{k}^{0}, T\right)$. Another user submodel, $g U s e r G i b b s$, was supplied to calculate the reduced spreading pressure for each component: $z_{k}=\int_{0}^{p_{k}^{0}} \frac{n_{k}^{0}}{P_{k}} \mathrm{~d} P_{k}$. The Gibbs integral was evaluated numerically by using a quadrature method (composite Simpson rule with 30 subintervals).

\section{RESULTS AND DISCUSSION}

Pure Component Equilibrium. The adsorption isotherms of $\mathrm{N}_{2}$ at $0,30,50$, and $70^{\circ} \mathrm{C}$ up to $120 \mathrm{kPa}$ are shown in Figure 2. The symbols represent the experimental data and the solid

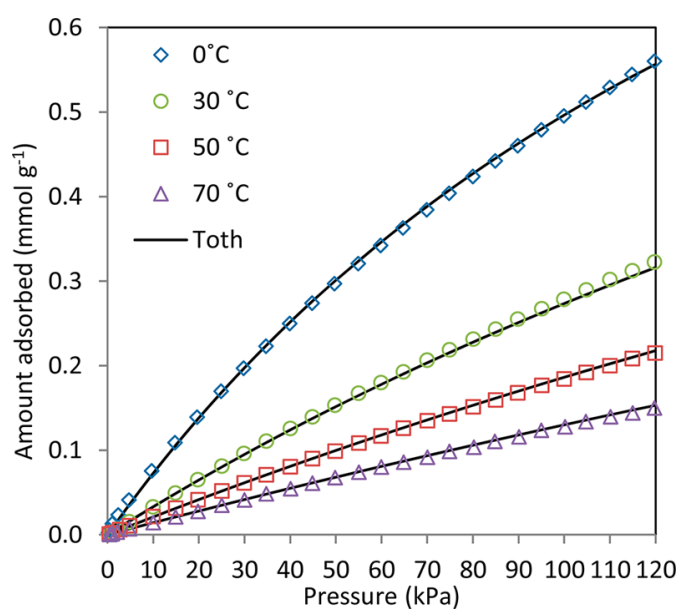

Figure 2. $\mathrm{N}_{2}$ adsorption isotherms at $0,30,50$, and $70{ }^{\circ} \mathrm{C}$ up to 120 $\mathrm{kPa}$. The symbols represent the experimental data and the solid lines the fitting provided by the Toth adsorption model.

lines the Toth adsorption model. The adsorption isotherms show a nearly linear behavior in the pressure and temperature range evaluated that can be adequately described by the Toth equation using the optimized parameters shown in Table 2.

The adsorption isotherms of $\mathrm{CO}_{2}$ at $0,30,50$, and $70{ }^{\circ} \mathrm{C}$ up to $120 \mathrm{kPa}$ are shown in Figure 3. The adsorption capacity for $\mathrm{CO}_{2}$ is substantially higher than that for $\mathrm{N}_{2}$ under the same conditions of temperature and pressure due to the higher quadrupole moment of the $\mathrm{CO}_{2}$ molecule (adsorption arises

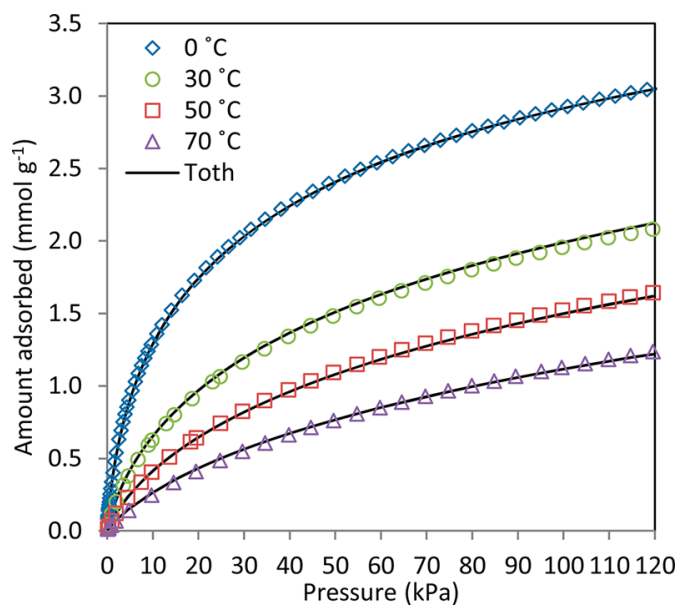

Figure 3. $\mathrm{CO}_{2}$ adsorption isotherms at $0,30,50$, and $70{ }^{\circ} \mathrm{C}$ up to 120 $\mathrm{kPa}$. The symbols represent the experimental data and the solid lines the fitting provided by the Toth adsorption model.

from relatively weak van der Waals forces between the biochar surface and these adsorbates). It can also be observed in Figure 3 that the Toth model adequately reproduces the experimental data for the adsorption of $\mathrm{CO}_{2}$ using the optimized parameters shown in Table 2 . As expected, the value of the heterogeneity parameter, $\tau$, of $\mathrm{CO}_{2}$ deviates greater from unity compared to that of $\mathrm{N}_{2}$. The parameter $Q$ represents the isosteric heat of adsorption given by the Toth model as $\tau$ has been considered temperature independent ${ }^{15}$ (in fact, parameter $\tau$ was allowed to vary with temperature following a linear relationship of empirical nature, ${ }^{15}$ but the optimal solution led to temperature invariance for $\mathrm{CO}_{2}$ ). As expected, the optimized value of $Q$ for $\mathrm{CO}_{2}$ is higher than that obtained for $\mathrm{N}_{2}$.

Figure 4 represents the isosteric heats of adsorption of $\mathrm{CO}_{2}$ and $\mathrm{N}_{2}$, calculated from the slope of the experimental isosteres,

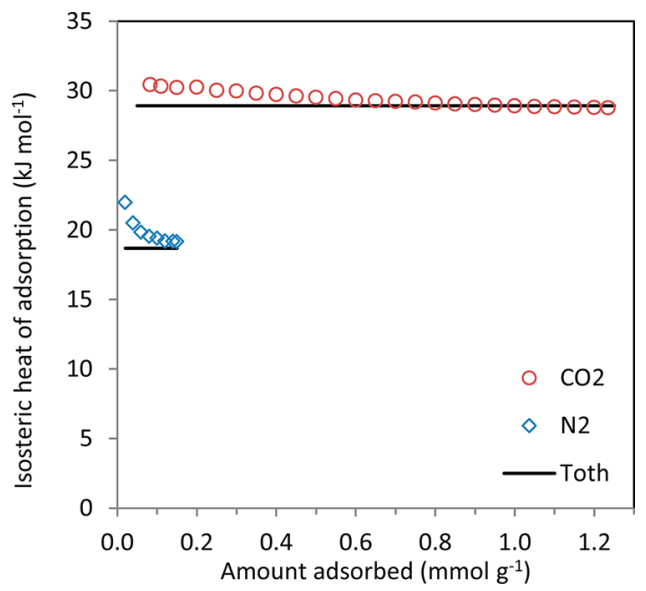

Figure 4. Isosteric heat of adsorption of $\mathrm{CO}_{2}$ and $\mathrm{N}_{2}$ over the evaluated biochar as a function of loading.

versus the amount adsorbed for each component (ClausiusClapeyron plots). Only the results for the isosteres showing a correlation coefficient greater than 0.99 are shown (the high linearity of the isosteres implies that the isosteric heat of adsorption can be considered nearly constant with temperature in the range evaluated). From Figure 4, it can be observed that the isosteric heat of adsorption of $\mathrm{CO}_{2}$ decreases only slightly for loadings between 0.08 and $1.24 \mathrm{~mol} \mathrm{~kg}^{-1}$, with values 
between 30 and $29 \mathrm{~kJ} \mathrm{~mol}^{-1}$, which are in good agreement with the value predicted by the Toth model. Figure 4 shows that the isosteric heat of adsorption of $\mathrm{N}_{2}$ decreases as the amount of $\mathrm{N}_{2}$ adsorbed increases at low loadings, below $0.08 \mathrm{~mol} \mathrm{~kg}^{-1}$. This is generally attributed to the adsorbent heterogeneity: the adsorption sites are filled in order of decreasing energies as pressure increases. ${ }^{32}$ A similar behavior should be expected for $\mathrm{CO}_{2}$ adsorption at low loadings; however, it is easier to obtain values of the isosteric heat of adsorption of $\mathrm{N}_{2}$ in this range due to its lower adsorption capacity compared to $\mathrm{CO}_{2}$ (the same loading is attained at higher pressure in the case of $\mathrm{N}_{2}$ ). The value of the parameter $Q$ of the Toth model for $\mathrm{N}_{2}$ matches the isosteric heat of adsorption of $\mathrm{N}_{2}$ at intermediate loadings. The values obtained for the isosteric heats of adsorption of $\mathrm{CO}_{2}$ and $\mathrm{N}_{2}$ are typical values for carbon adsorbents., 11

Binary Breakthrough Experiments. Figure 5 represents the response of the adsorption unit in the absence of

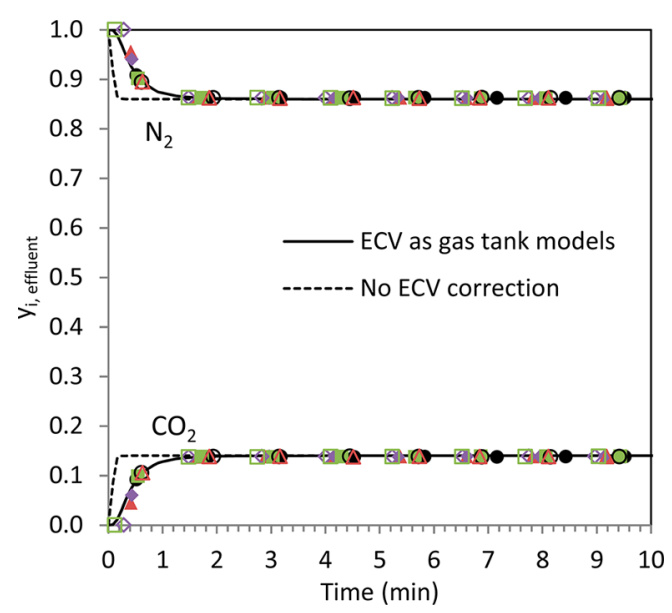

Figure 5. Response of the fixed-bed adsorption unit when the adsorber is loaded with glass beads $(D=2 \mathrm{~mm})$ to a step change in the feed composition from $100 \% \mathrm{~N}_{2}$ to $86 \% \mathrm{~N}_{2}$ and $14 \% \mathrm{CO}_{2}$ (feed flow rate: $140 \mathrm{~cm}^{3} \mathrm{~min}^{-1}$, STP). The symbols represent the experimental results from eight different runs; the solid lines, the simulation results using gas tank models to account for the Extra-Column Volume (ECV); and dashed lines, the simulation results without considering the ECV.

adsorption (adsorber filled with glass beads) to a step change in the feed composition from $100 \% \mathrm{~N}_{2}$ to $86 \% \mathrm{~N}_{2}$ and $14 \%$ $\mathrm{CO}_{2}$ using a feed flow rate of $140 \mathrm{~cm}^{3} \mathrm{~min}^{-1}$ (STP). The symbols represent the experimental results of eight consecutive runs. The solid lines represent the results of a simulation run in which the ECV has been accounted for using a series of gas tank void models (see DVBA, DVAA, RH, C, and D in Figure 1), and the dashed lines represent the results of a simulation run in which the ECV was not considered. It can be observed that even in the absence of adsorption, the experimental curves present a small delay and dispersion compared to the input step signal at $t=0$. As can be seen from Figure 5, the agreement between the experimental and the simulation results is greatly improved by using the gas_tank_void models to account for the ECV.

Figure 6 presents the results of case 1: response of the adsorption unit when the adsorber is filled with $7 \mathrm{~g}$ of biochar to a step change in the feed composition from $100 \% \mathrm{~N}_{2}$ to $92 \%$ $\mathrm{N}_{2}$ and $8 \% \mathrm{CO}_{2}$ at $140 \mathrm{kPa}$ and at room temperature using a feed flow rate of $140 \mathrm{~cm}^{3} \mathrm{~min}^{-1}$ (STP). Figure $6 \mathrm{a}$ and $\mathrm{b}$ show the evolution of $\mathrm{CO}_{2}$ and $\mathrm{N}_{2}$ molar fractions in the effluent, respectively. Figure $6 \mathrm{c}$ represents the mass flow rate measured by the coriolis meter, and Figure $6 \mathrm{~d}$ represents the temperature of the adsorber at $4.7 \mathrm{~cm}$ from the feed end. The symbols represent the experimental results and the lines, the results obtained by simulation using the kinetic model Particle MB with the mass and heat transfer coefficients shown in Table 3. Two simulation runs are compared: the solid lines represent the results from the simulation run in which the equilibrium of adsorption of $\mathrm{CO}_{2}$ and $\mathrm{N}_{2}$ was modeled making use directly of the pure component models (Toth equation), and the dashed lines represent the results from the simulation run in which the competitive adsorption has been accounted for by using the IAS theory. The predictions obtained using the pure component adsorption models would hold true for a hypothetical situation in which there is an absence of competition between the adsorbates for the pore volume. However, in reality, the adsorbates need to compete for the available pore volume. As can be seen from Figure $6 a$ and $b$, over nearly $4 \mathrm{~min}$, all the $\mathrm{CO}_{2}$ is retained by the adsorbent, and a fully decarbonized effluent leaves the adsorber, which ratifies the selectivity of the biochar toward $\mathrm{CO}_{2}$ over $\mathrm{N}_{2}$. From this point onward, the $\mathrm{CO}_{2}$ molar fraction in the effluent starts to increase until it meets that of the feed (the adsorbent becomes fully saturated). The thermal wave observed as a consequence of $\mathrm{CO}_{2}$ adsorption (Figure $6 \mathrm{~d}$ ) is rather small $\left(\Delta T_{\max } \approx 3{ }^{\circ} \mathrm{C}\right.$ ), which is in good agreement with the moderate value of the isosteric heat of adsorption of $\mathrm{CO}_{2}$ on the evaluated biochar. This is one of the advantages of using carbon adsorbents, as the temperature rise that takes place during the adsorption step contributes to reducing the working capacity of the adsorbent. As can be observed from Figure 6, the IAS-based simulation provides a better fit of the experimental curves compared to the simulation based on the pure components models (note that only the effective diffusivity of the adsorbed phase was fitted to reproduce the experimental data; the values are summarized in Table 3). Figure $6 \mathrm{c}$ shows that the mass flow rate of the effluent prior to the breakthrough of $\mathrm{CO}_{2}$ is lower for the simulation carried out with the pure component adsorption models, as it does not reproduce the displacement of part of the $\mathrm{N}_{2}$ initially adsorbed by the preferential adsorption of $\mathrm{CO}_{2}$ (generally referred to as roll-up). Likewise, the thermal wave associated with the adsorption of $\mathrm{CO}_{2}$, shown in Figure $6 \mathrm{~d}$, is larger for the simulation carried out with the pure component adsorption models, given that it does not take into consideration the heat consumed to desorb that $\mathrm{N}_{2}$ (both simulation runs were carried out using the same heat and mass transfer coefficients, shown in Table 3).

The cumulative amount of $\mathrm{CO}_{2}$ adsorbed versus time, calculated from the experimental data making use of eq 4 , is best matched by the IAS-based simulation (see Figure 6e). At equilibrium, this is $0.70 \mathrm{mmol} \mathrm{g}^{-1}$, which is $12 \%$ lower than that given by the pure component equilibrium-based simulation. Although pure component adsorption models are often employed to run simulations of multicomponent adsorption for the sake of simplicity, the improvement of the model accounting for competitive adsorption is clearly significant under the current scenario.

The $\mathrm{CO}_{2}$ over $\mathrm{N}_{2}$ separation factor is defined as the quotient between the ratio of the adsorbed composition and the ratio of the gas phase composition $S_{\mathrm{CO}_{2} / \mathrm{N}_{2}}=\frac{x \mathrm{CO}_{2} / x_{\mathrm{N}_{2}}}{y \mathrm{CO}_{2} / y_{\mathrm{N}_{2}}}$ where $x$ represents the molar fraction of the adsorbed phase and $y$ represents the molar fraction of the gas phase. The $\mathrm{CO}_{2} / \mathrm{N}_{2}$ 
(a)

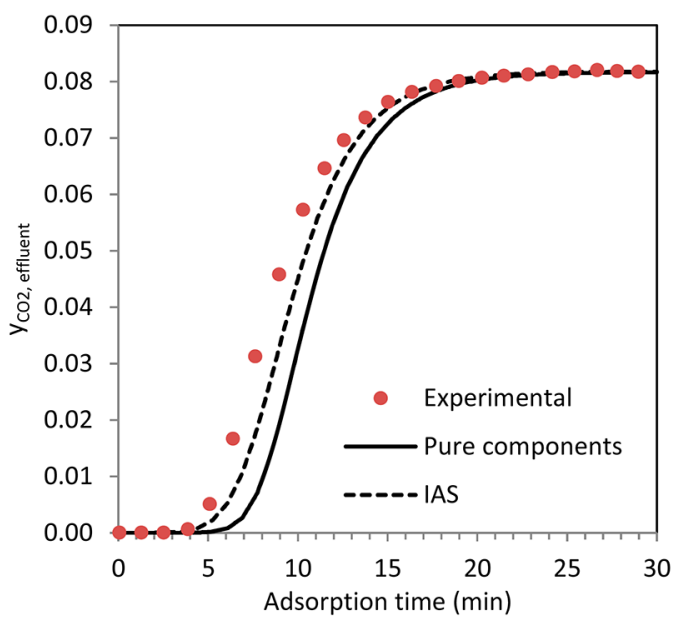

(c)

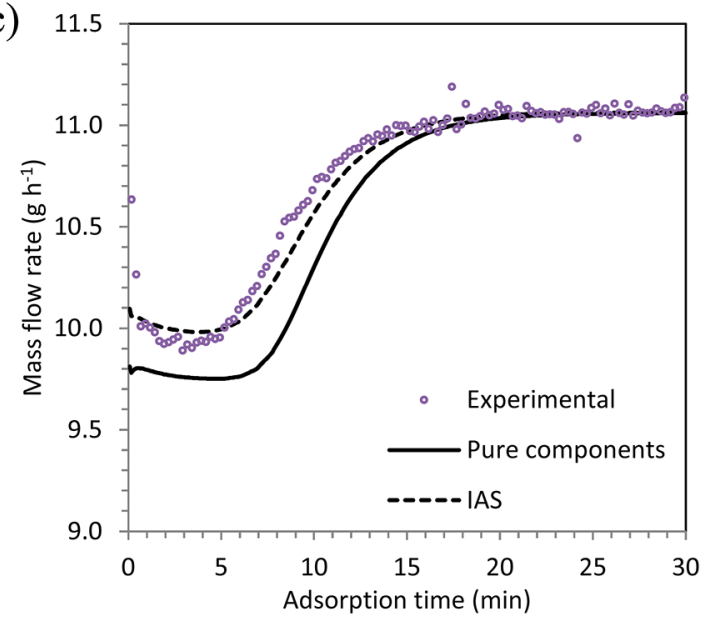

(e)

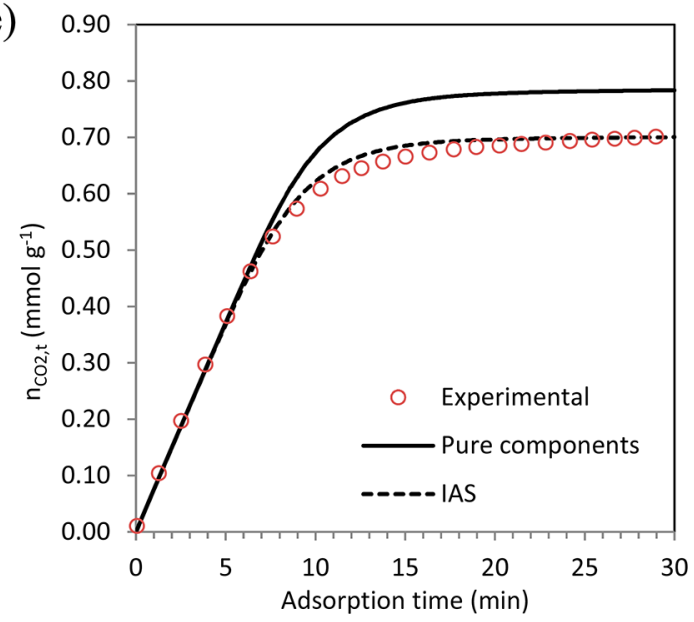

(b)

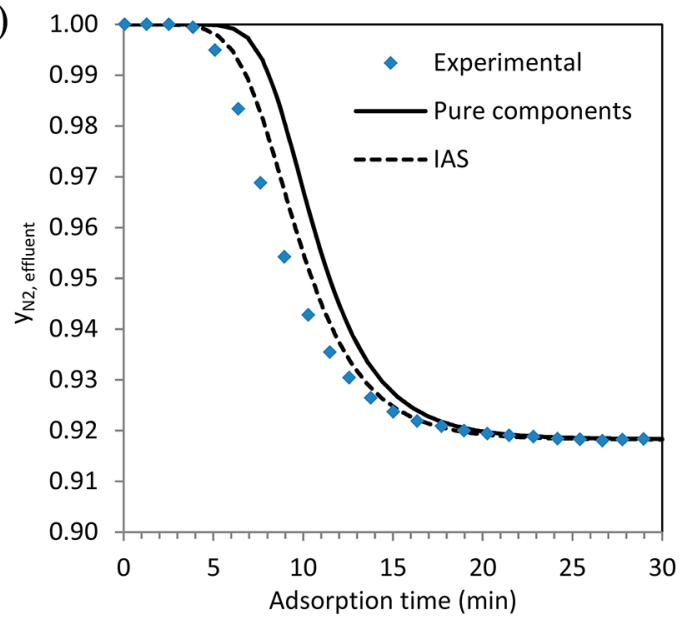

(d)

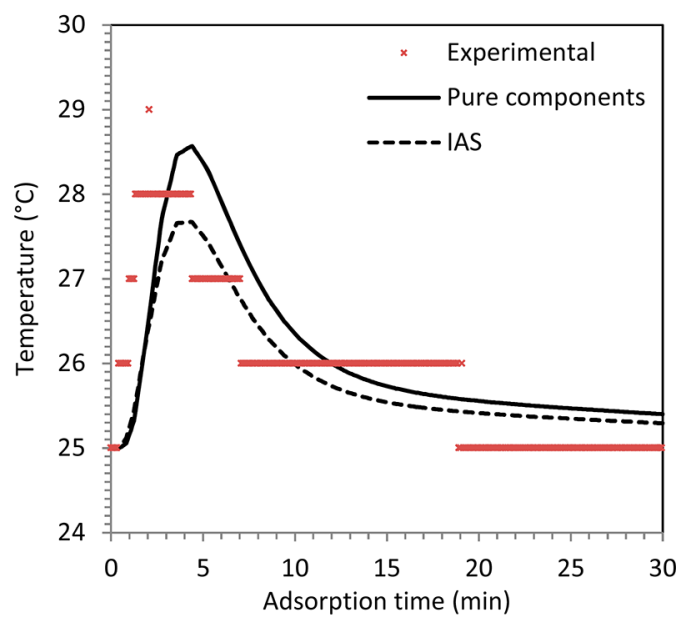

Figure 6. Case 1: breakthrough curve of a mixture with $8 \% \mathrm{CO}_{2}$ (balance $\mathrm{N}_{2}$ ) at $140 \mathrm{kPa}$ and room temperature (feed flow rate: $140 \mathrm{~cm}^{3} \mathrm{~min}-1$, STP): molar fraction of (a) $\mathrm{CO}_{2}$ and (b) $\mathrm{N}_{2}$ in the effluent; (c) mass flow rate of the effluent; (d) temperature of the bed at $4.7 \mathrm{~cm}$ from the feed end; (e) cumulative amount of $\mathrm{CO}_{2}$ adsorbed. The symbols represent the experimental data and the lines, the results obtained by simulation (the solid lines represent the results based on the pure component adsorption models and the dashed lines, the results based on IAS theory).

separation factor was calculated using the data from the two simulation runs. IAS theory, which provides a better description of the experimental results, predicts a value of the $\mathrm{CO}_{2}$ over $\mathrm{N}_{2}$ separation factor of 40, which is much higher than that estimated making use of the pure component models (24). The IAS theory predicts that the adsorption of $\mathrm{CO}_{2}$ (strong adsorbate) is reduced by $11 \%$ compared to the pure component model, while the adsorption of $\mathrm{N}_{2}$ (weak adsorbate) is reduced by $46 \%$ in the experimental conditions evaluated. Although the use of the pure component models to calculate the separation factor is an extended practice, it can lead to erroneous conclusions due to the significant overestimation of the amount of weak adsorbate adsorbed.

A third simulation of case 1 was carried out using the IAS theory to account for competitive adsorption, but changing the kinetic model from particle $M B$, to lumped resistance, assuming a 
(a)

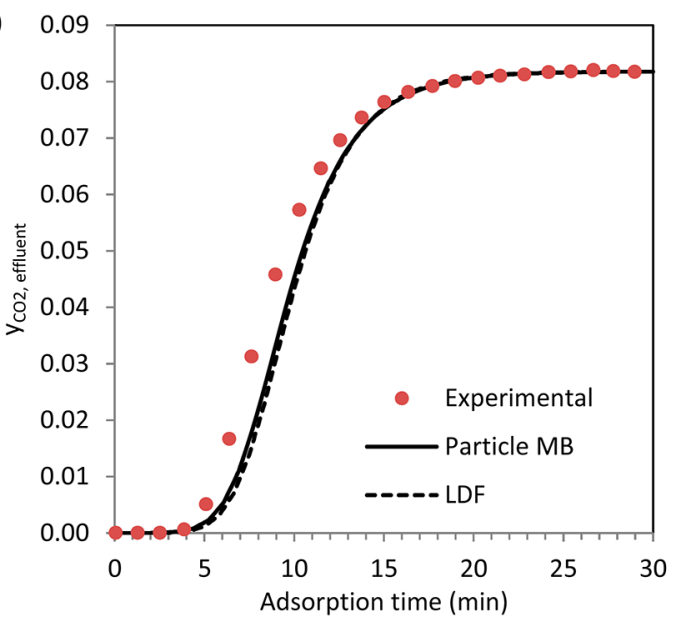

(c)

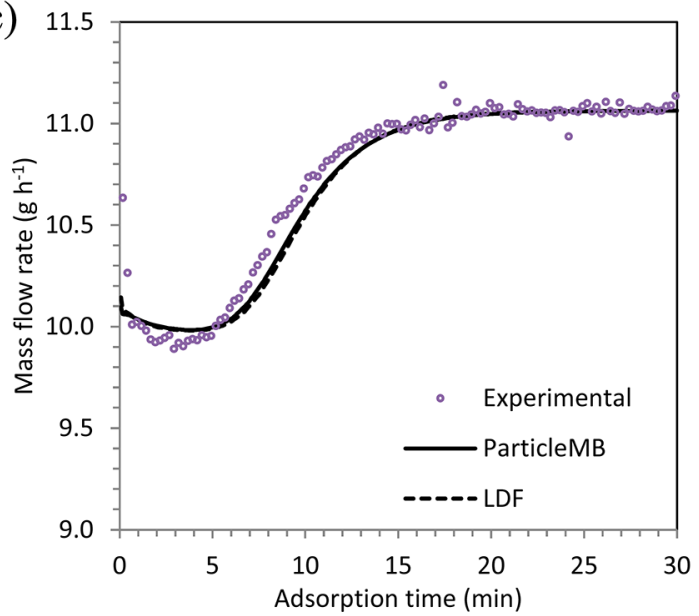

(b)

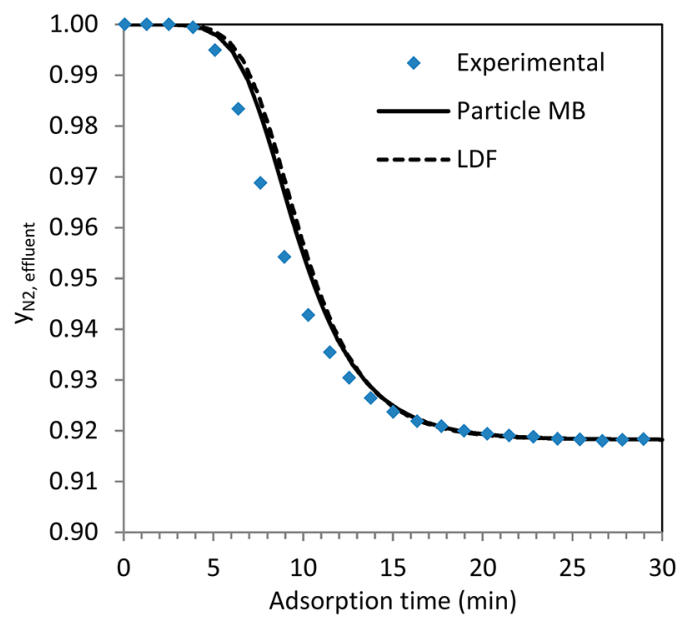

(d)

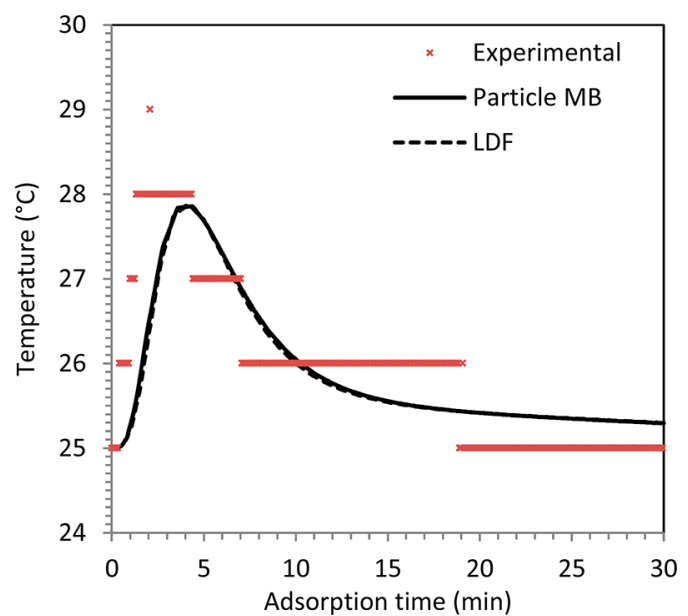

Figure 7. Influence of the kinetic model for case 1: molar fraction of (a) $\mathrm{CO}_{2}$ and (b) $\mathrm{N}_{2}$ in the effluent; (c) mass flow rate; (d) temperature of the bed at $4.7 \mathrm{~cm}$ from the feed end. The symbols represent the experimental data, and the lines represent the results obtained by the IAS-based simulation using two different kinetic models: lumped resistance based on solid phase LDF approximation (LDF, dashed lines) and particle MB (solid lines).

constant overall mass transfer coefficient (MTC), calculated from the previously fitted effective diffusivity coefficient by MTC $=15 D_{\mathrm{e}} / R_{\mathrm{p}}{ }^{2}$, where $R_{\mathrm{p}}$ represents the average particle radius (assuming particles of nearly spherical shape). ${ }^{33}$ As can be seen from Figure 7, the results are coincident in both cases, which means that eventually both kinetic models could be used for design purposes with similar accuracy. Similar results were obtained for the rest of the cases evaluated in the present work. The LDF approach has the advantage of a lesser computational effort.

Figure 8 summarizes the experimental and simulation results for case 2, which was carried out under similar conditions than case 1 but with a greater $\mathrm{CO}_{2}$ content in the feed: $14 \%$ (see Table 3 for further details). The breakthrough time observed experimentally is slightly reduced compared to case 1 due to the greater flow rate of $\mathrm{CO}_{2}$ fed to the adsorber, although this is partially compensated by the greater adsorption capacity at the higher partial pressure of $\mathrm{CO}_{2}$ in the gas phase. The thermal wave associated with $\mathrm{CO}_{2}$ adsorption $\left(\Delta T_{\max }=4{ }^{\circ} \mathrm{C}\right)$ is slightly greater than that observed for case 1 due to the greater amount of $\mathrm{CO}_{2}$ adsorbed in a slightly shorter time. As can be seen from Figure 8 , the IAS-based simulation provides a better fit of the experimental curves compared to the simulation run based on the pure component adsorption models. The mass flow rate observed experimentally before the breakthrough of $\mathrm{CO}_{2}$
(Figure 8c) lies between the two simulation runs, which apparently indicates that the amount of $\mathrm{N}_{2}$ actually displaced by the preferential adsorption of $\mathrm{CO}_{2}$ is somewhat lower than that predicted by IAS. The amount of $\mathrm{CO}_{2}$ adsorbed at equilibrium, estimated from the experimental data, is $0.93 \mathrm{mmol} \mathrm{g}^{-1}$, which is $15 \%$ lower than that given by the pure component model and $6 \%$ lower than that predicted by IAS (Figure 8e). The IAS method predicts a value of the $\mathrm{CO}_{2} / \mathrm{N}_{2}$ separation factor of 42 (slightly superior than that of case 1 ), which, as expected, is much higher than that calculated making use of the pure component models (19) given that IAS predicts a reduction of the $\mathrm{CO}_{2}$ adsorption capacity of only $8 \%$ compared to the pure component model, and of $59 \%$ for $\mathrm{N}_{2}$ in the experimental conditions evaluated.

Figure 9 summarizes the results of case 3, which was carried out under similar conditions to case 1 and case 2 except for the greater content of $\mathrm{CO}_{2}$ in the feed: $30 \%$. The breakthrough time of $\mathrm{CO}_{2}$ (Figure 9a) is slightly lower than that of case 2, following the expected trend. Likewise, the thermal wave associated with the exothermic adsorption of $\mathrm{CO}_{2}$ increases as the concentration of $\mathrm{CO}_{2}$ in the feed increases $\left(\Delta T_{\max }=9{ }^{\circ} \mathrm{C}\right)$, due to the greater amount of $\mathrm{CO}_{2}$ adsorbed in a slightly shorter time. The IAS-based simulation shows a close pattern for the $\mathrm{CO}_{2}$ and $\mathrm{N}_{2}$ curves compared to the pure component-based simulation (Figure 9a and b). Differences between both 
(a)

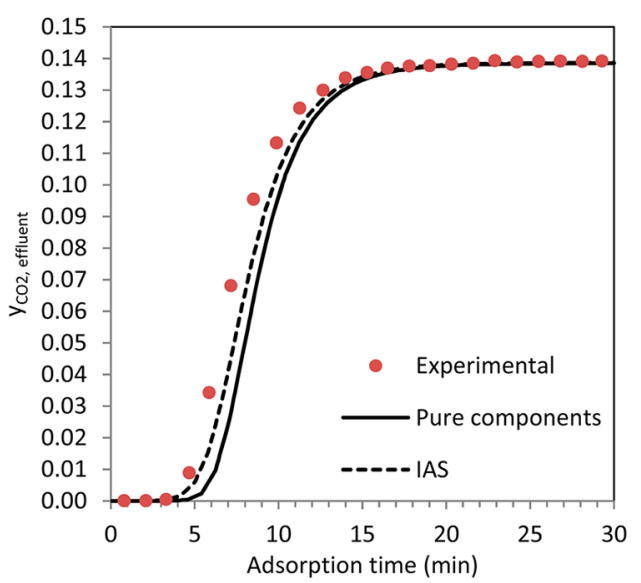

(c)

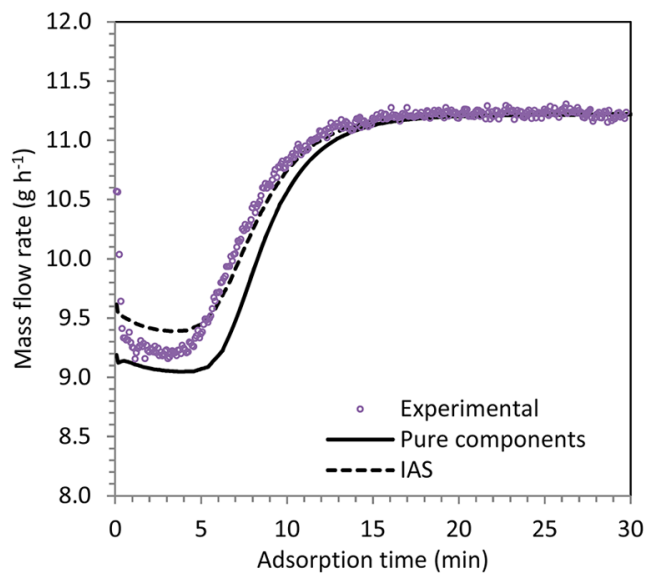

(e)

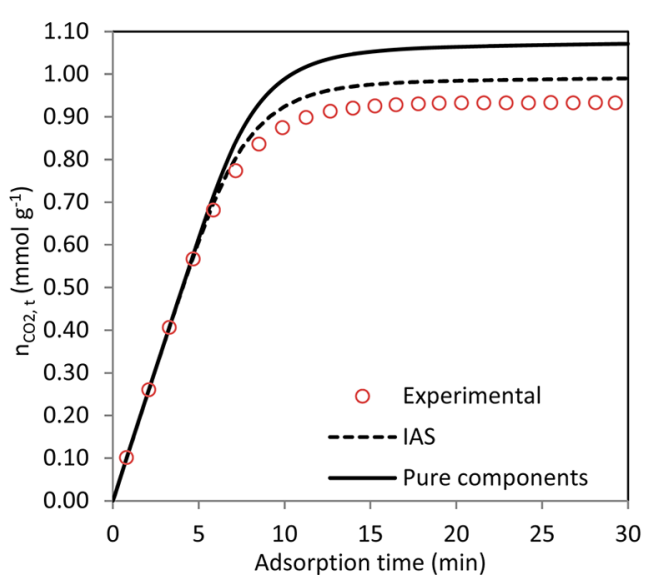

(b)

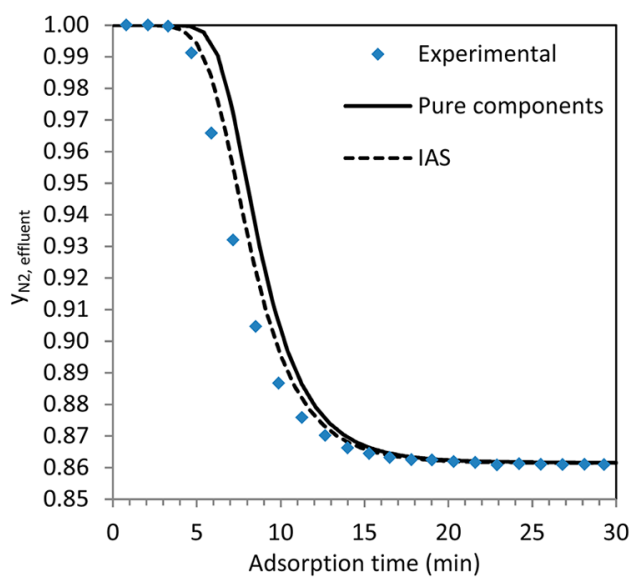

(d)

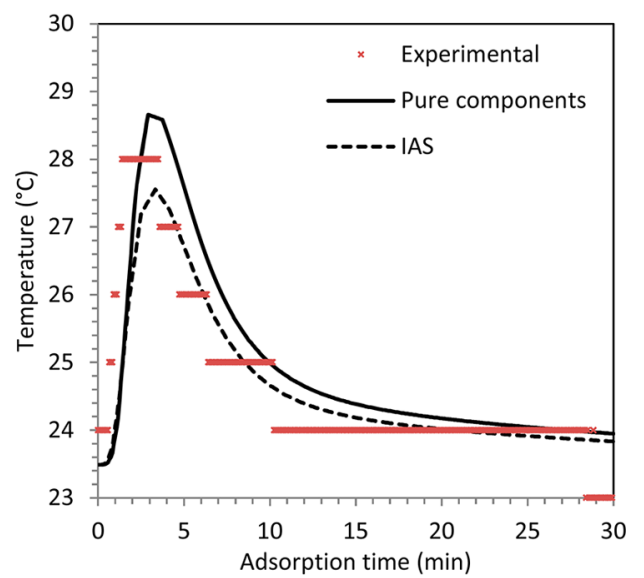

Figure 8. Case 2: breakthrough curve of a mixture with $14 \% \mathrm{CO}_{2}$ (balance $\mathrm{N}_{2}$ ) at $140 \mathrm{kPa}$ and room temperature (feed flow rate: $140 \mathrm{~cm}^{3} \mathrm{~min}^{-1}$, STP): molar fraction of (a) $\mathrm{CO}_{2}$ and (b) $\mathrm{N}_{2}$ in the effluent; (c) mass flow rate of the effluent; (d) temperature of the bed at $4.7 \mathrm{~cm}$ from the feed end; (e) cumulative amount of $\mathrm{CO}_{2}$ adsorbed. The symbols represent the experimental data and the lines, the results obtained by simulation (the solid lines represent the results based on the pure component adsorption models and the dashed lines, the results based on IAS theory).

simulation runs can be better appreciated in the mass flow rate and the temperature history (Figure $9 \mathrm{c}$ and d, respectively) due to the effect of $\mathrm{N}_{2}$ desorption by the preferential adsorption of $\mathrm{CO}_{2}$ as already discussed for case 1 and case 2 . As can be seen from the figures, both simulation runs provide a satisfactory description of the experimental curves, although the IAS-based simulation provides a better fit of the thermal wave associated with the adsorption of $\mathrm{CO}_{2}$. The amount of $\mathrm{CO}_{2}$ adsorbed at equilibrium, estimated from the experimental results is 1.48 mmol g ${ }^{-1}$, which is slightly above that calculated by the IASbased simulation (2\%) and slightly below (1\%) that calculated by the simulation based on the pure component equilibrium models (Figure 9e). IAS theory predicts a reduction in the adsorption capacity of only $4 \%$ for $\mathrm{CO}_{2}$, but of $76 \%$ for $\mathrm{N}_{2}$ compared to the pure component models, which leads to a $\mathrm{CO}_{2} / \mathrm{N}_{2}$ separation factor of 47 , which is significantly above that expected for the pure components (12).

As shown for cases 1 to 3 , as the partial pressure of $\mathrm{CO}_{2}$ increases, multicomponent prediction for the adsorption of $\mathrm{CO}_{2}$ tends to that of the pure component model; meanwhile the adsorption capacity of $\mathrm{N}_{2}$ drops drastically, boosting the $\mathrm{CO}_{2} / \mathrm{N}_{2}$ separation factor compared to that estimated from the pure component adsorption models. 
(a)

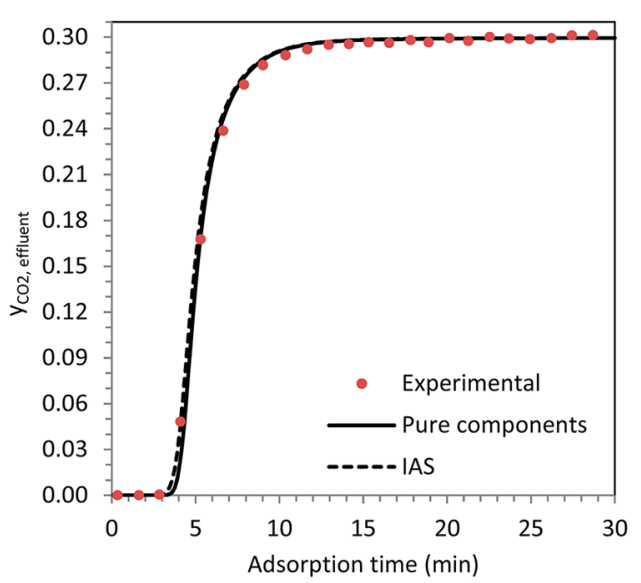

(c)

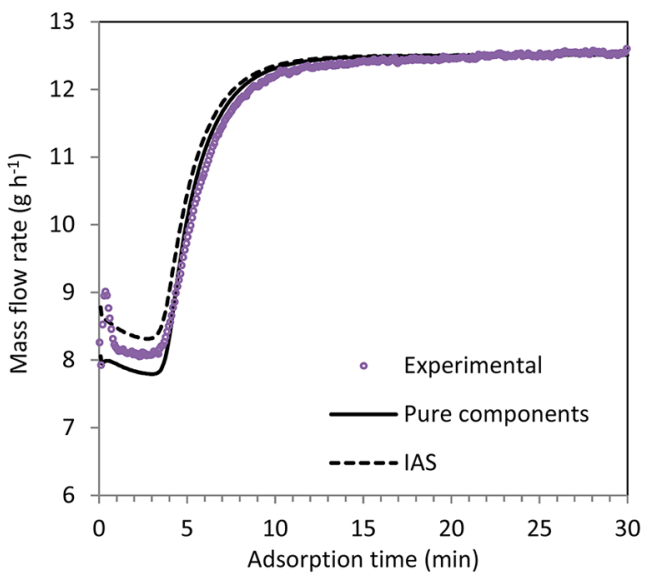

(e)

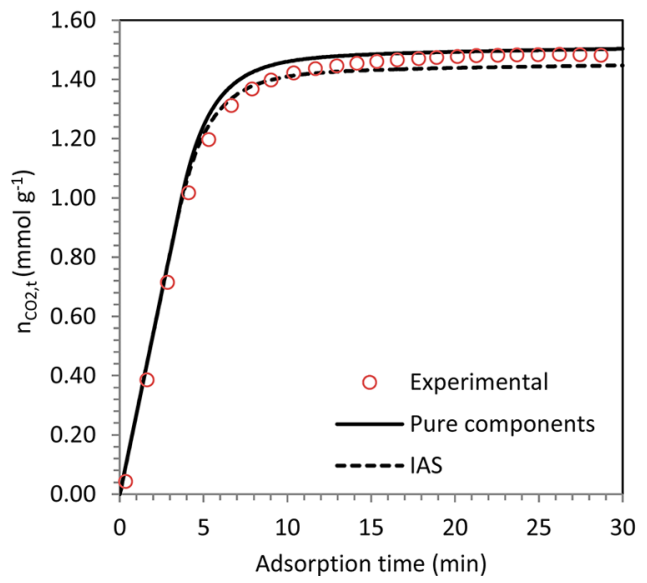

(b)

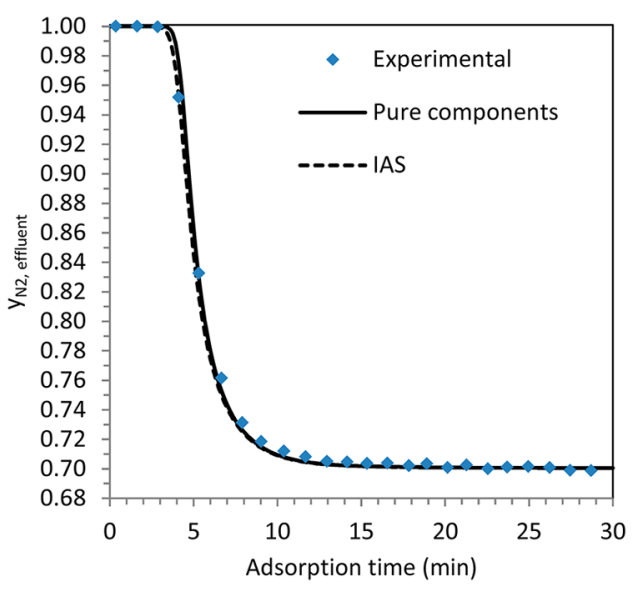

(d)

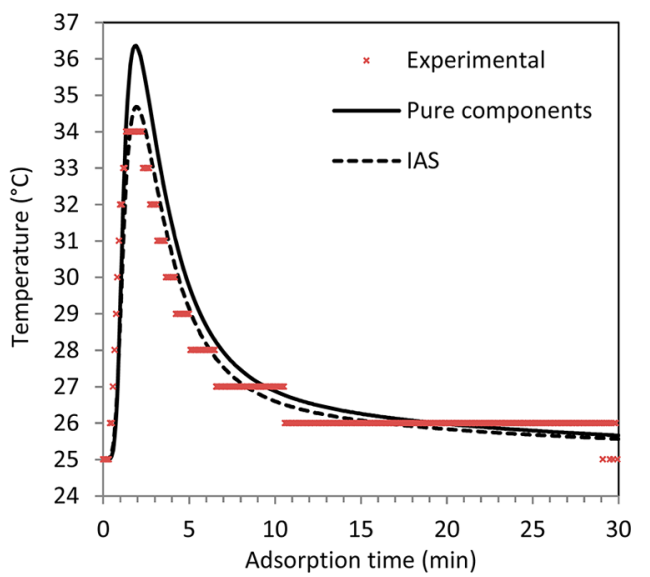

Figure 9. Case 3: breakthrough curve of a mixture with $30 \% \mathrm{CO}_{2}$ (balance $\mathrm{N}_{2}$ ) at $140 \mathrm{kPa}$ and room temperature (feed flow rate: $140 \mathrm{scm}^{3} \mathrm{~min}{ }^{-1}$, STP): molar fraction of (a) $\mathrm{CO}_{2}$ and (b) $\mathrm{N}_{2}$ in the effluent; (c) mass flow rate of the effluent; (d) temperature of the bed at $4.7 \mathrm{~cm}$ from the feed end; (e) cumulative amount of $\mathrm{CO}_{2}$ adsorbed. The symbols represent the experimental data and the lines, the results obtained by simulation (the solid lines represent the results based on the pure component adsorption models and the dashed lines, the results based on IAS theory).

Figure 10 represents the results of case 4 . The breakthrough time of $\mathrm{CO}_{2}$ is lower than that of case 2 due to the increase in the adsorption temperature (see Table 3). It can be observed from Figure 10 that the IAS-based simulation provides a better description of the experimental data than that based on the pure component adsorption models (see for example the goodness of fit of the mass flow rate in Figure 10c). The amount of $\mathrm{CO}_{2}$ adsorbed at equilibrium, estimated from the experimental data, is $0.59 \mathrm{mmol} \mathrm{g}^{-1}$, which is $2 \%$ lower than that calculated by the IAS-based simulation and $9 \%$ lower than that of the simulation based on the pure component models. IAS predicts a reduction in the adsorption capacity of $7 \%$ for
$\mathrm{CO}_{2}$ and of $43 \%$ for $\mathrm{N}_{2}$ compared to the pure component models, which leads to a separation factor of 29 . This value is significantly lower than that obtained at room temperature under the same partial pressure of $\mathrm{CO}_{2}$ (case 2).

Figure 11 represents the results for case 5, which was carried out under similar conditions to case 2 and case 4 except for the higher adsorption temperature: $70{ }^{\circ} \mathrm{C}$. As can be seen from Figure 11a, the breakthrough time of $\mathrm{CO}_{2}$ is additionally reduced compared to case 4 due to the increase in the adsorption temperature that decreases the equilibrium adsorption capacity. From Figure 11, it can be observed that the simulation carried out making use of IAS leads to a better fit 
(a)

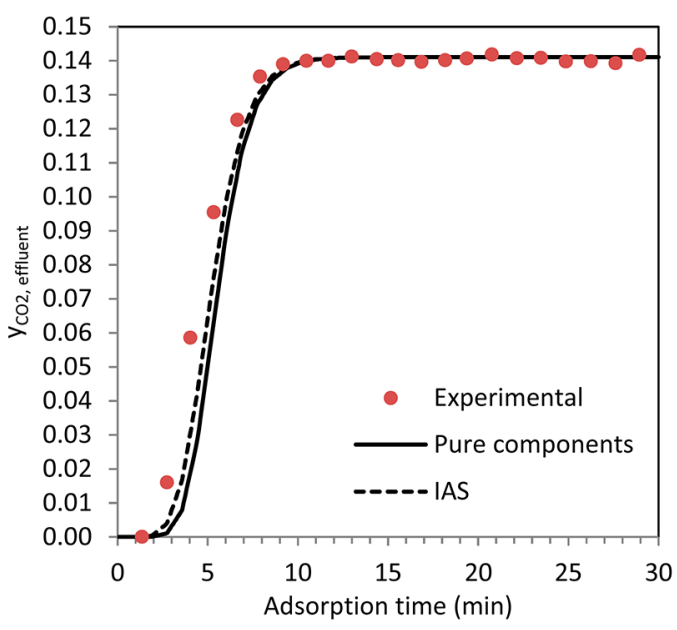

(c)

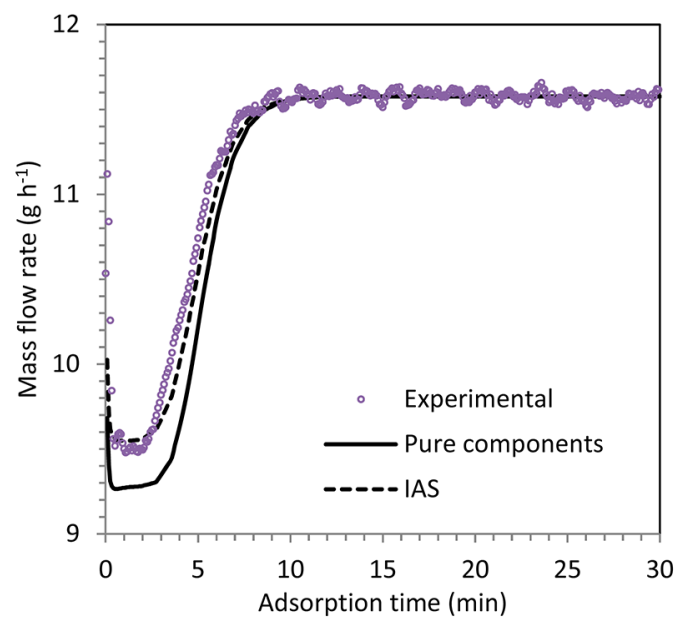

(e)

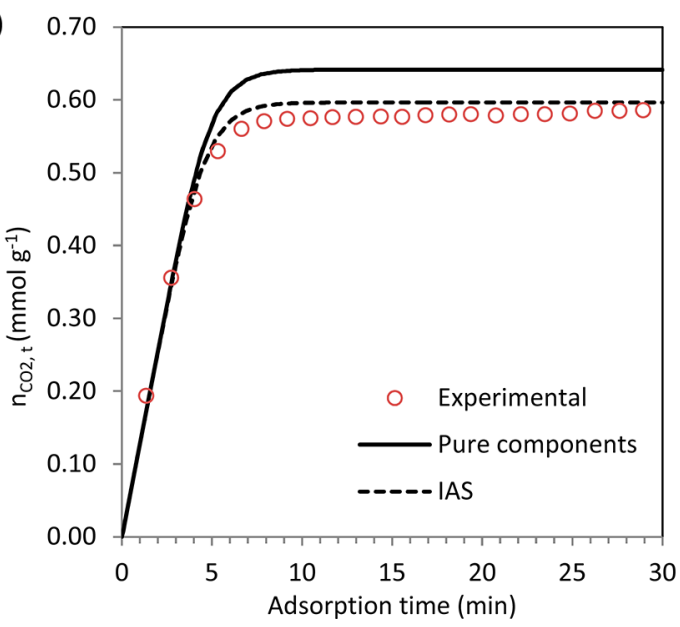

(b)

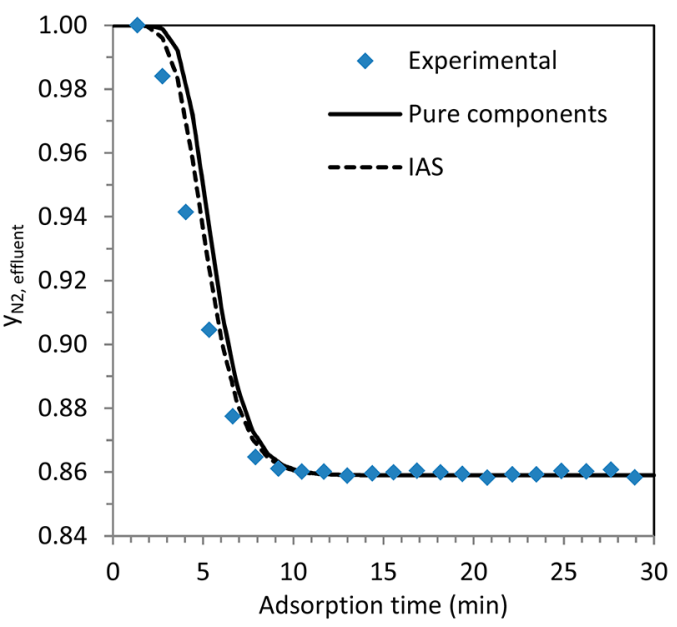

(d)

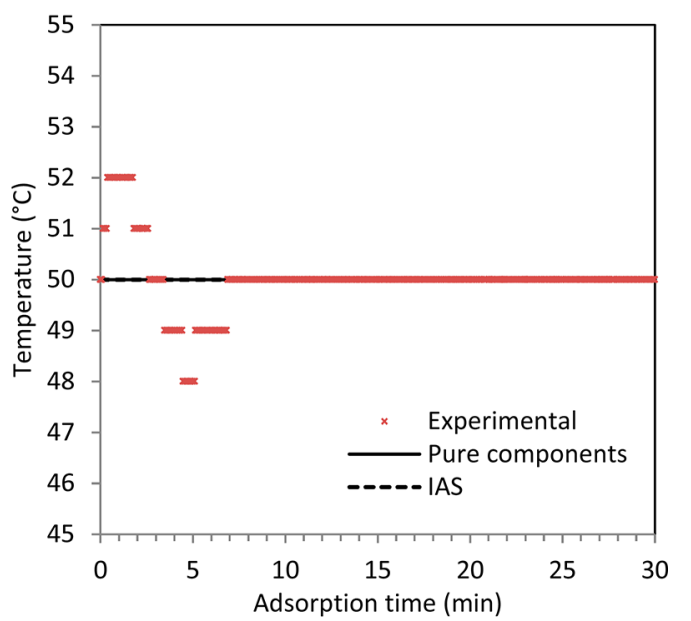

Figure 10. Case 4: breakthrough curve of a mixture with $14 \% \mathrm{CO}_{2}$ (balance $\mathrm{N}_{2}$ ) at $140 \mathrm{kPa}$ and $50{ }^{\circ} \mathrm{C}$ (feed flow rate: $140 \mathrm{~cm}^{3} \mathrm{~min}^{-1}$, STP): $\mathrm{molar}$ fraction of (a) $\mathrm{CO}_{2}$ and (b) $\mathrm{N}_{2}$ in the effluent; (c) mass flow rate of the effluent; (d) temperature of the bed at $4.7 \mathrm{~cm}$ from the feed end; (e) cumulative amount of $\mathrm{CO}_{2}$ adsorbed. The symbols represent the experimental data and the lines, the results obtained by simulation (the solid lines represent the results based on the pure component adsorption models and the dashed lines, the results based on IAS theory).

of the experimental data compared to the simulation run based on the pure component adsorption models. The amount of $\mathrm{CO}_{2}$ adsorbed at equilibrium, estimated from the experimental data is $0.38 \mathrm{mmol} \mathrm{g}^{-1}$, which is $14 \%$ lower than that obtained by the simulation based on the pure component adsorption models and 7\% lower than that of the IAS-based simulation. IAS predicts a reduction in the amount of $\mathrm{N}_{2}$ adsorbed of $33 \%$ compared to the pure component model, and of $6 \%$ for $\mathrm{CO}_{2}$, which leads to a separation factor of 24 , higher than that calculated making use of the pure components models (17).

As mentioned in the Materials and Methods section, only the values of the effective diffusivities were fitted to reproduce the experimental data for each case. It was found that the effective diffusivity increased with temperature following an exponential trend, which is the expected behavior for a surface diffusion activated process, in which the diffusivity depends on 
(a)

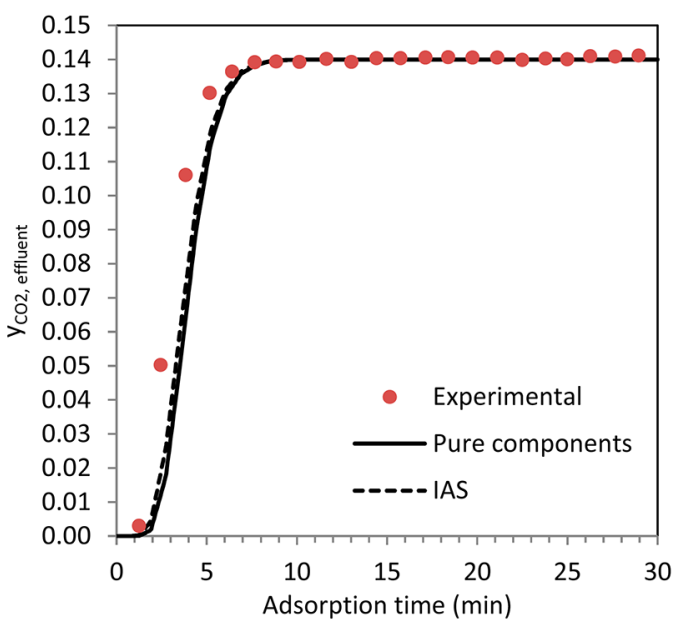

(c)

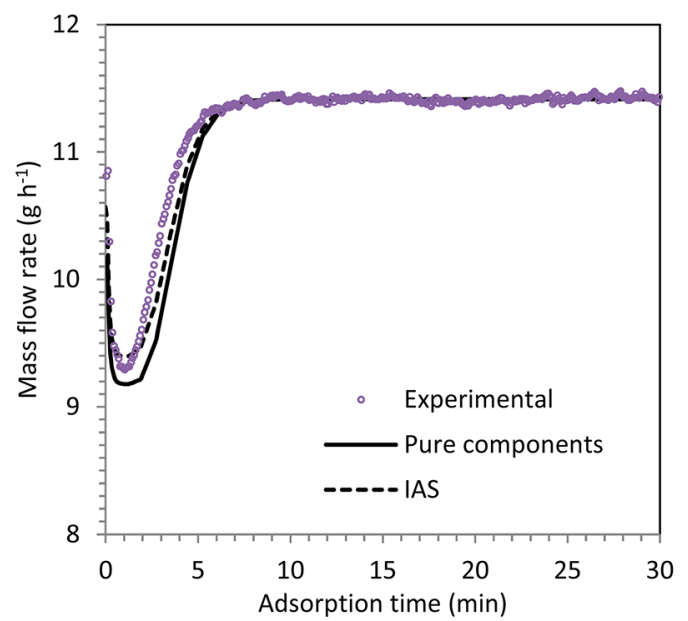

(e)

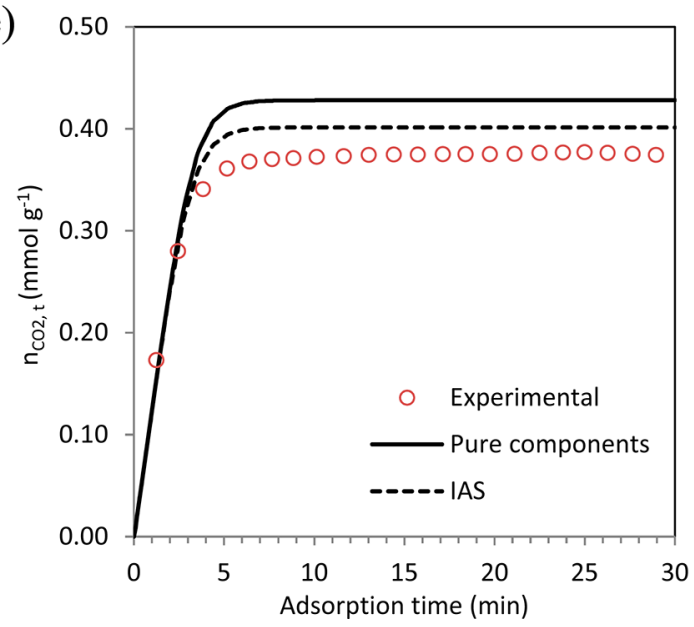

(b)

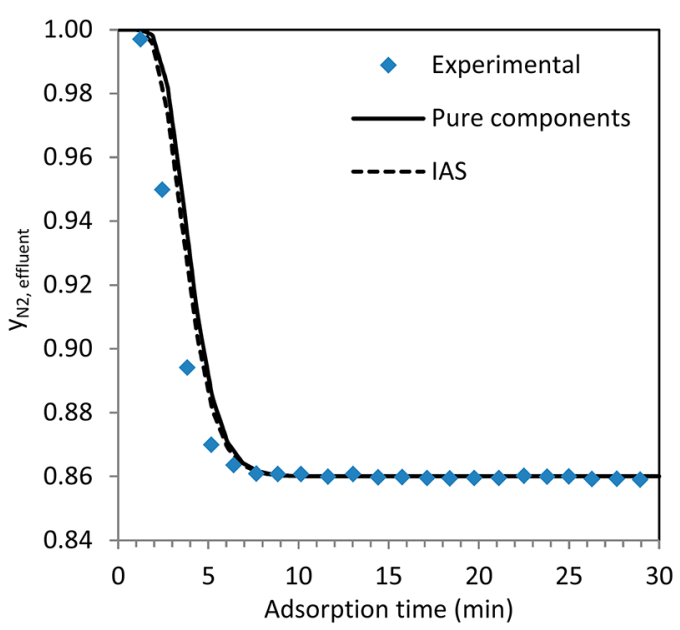

(d)

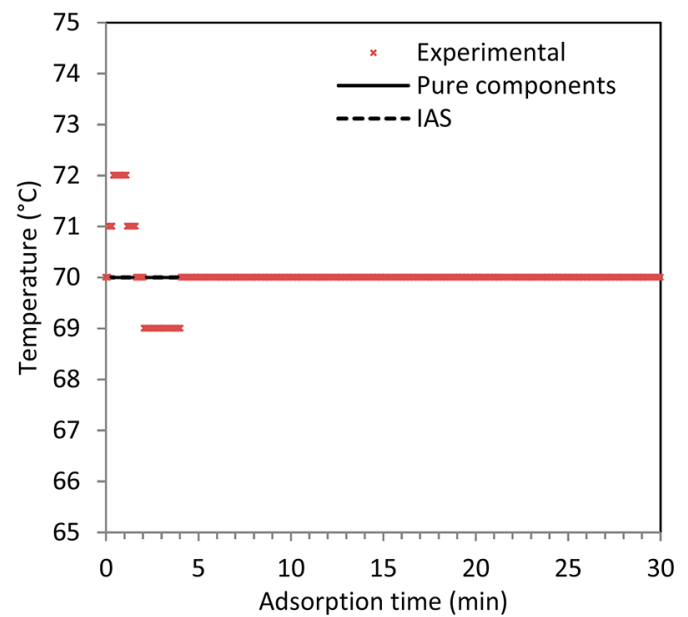

Figure 11. Case 5: breakthrough curve of a binary mixture with $14 \% \mathrm{CO}_{2}$ (balance $\mathrm{N}_{2}$ ) at $140 \mathrm{kPa}$ and $70{ }^{\circ} \mathrm{C}$ (feed flow rate: $140 \mathrm{scm}^{3} \mathrm{~min}^{-1}$, STP): molar fraction of (a) $\mathrm{CO}_{2}$ and (b) $\mathrm{N}_{2}$ in the effluent; (c) mass flow rate of the effluent; (d) temperature of the bed at $4.7 \mathrm{~cm}$ from the feed end; (e) cumulative amount of $\mathrm{CO}_{2}$ adsorbed. The symbols represent the experimental data and the lines, the results obtained by simulation (the solid lines represent the results based on the pure component adsorption models and the dashed lines, the results based on IAS theory).

temperature according to the following expression: $D=$ $D_{\mathrm{o}} \mathrm{e}^{-E_{\mathrm{a}} / R T}$, where $D_{\mathrm{o}}$ is the diffusivity pre-exponential factor and $E_{\mathrm{a}}$ is the activation energy for surface diffusion. ${ }^{34}$ By plotting $\ln (D)$ vs $1 / T$ for the values of the effective diffusivity used to run the simulations (Table 3), a straight line is obtained with a regression coefficient of 1.000 . The value of the activation energy obtained by this regression is $35.8 \mathrm{~kJ} \mathrm{~mol}^{-1}$, which is higher than expected, as the activation energy for surface diffusion is generally lower than the heat of adsorption. ${ }^{15,35}$ Repulsive forces between the diffusing molecule and the pore entrance could result in activation energies higher than the isosteric heat of adsorption. ${ }^{36}$ Despite the uncertainty in the value of the activation energy, the exponential dependence of the effective diffusivity observed with temperature points out that the rate limiting step of the adsorption process is surface diffusion. Molecular diffusion in 
(a)

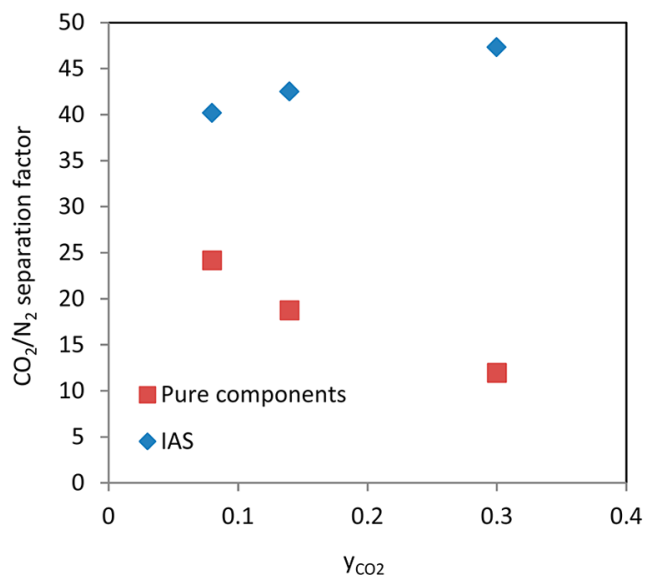

(b)

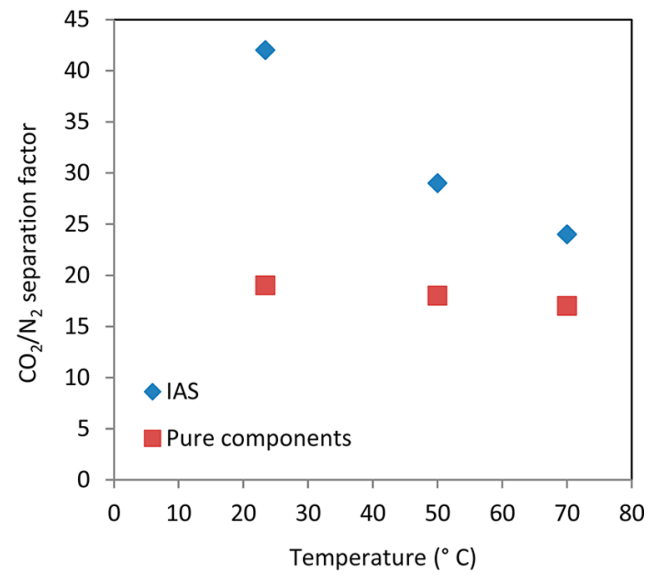

Figure 12. Comparison of the $\mathrm{CO}_{2} / \mathrm{N}_{2}$ separation factor calculated using the pure component models and the IAS theory at a total pressure of 140 $\mathrm{kPa}$ : (a) influence of the molar fraction of $\mathrm{CO}_{2}$ in the gas phase at room temperature; (b) influence of temperature for a gas phase with $14 \% \mathrm{CO}_{2}$.

the boundary layer and pore diffusion, which is a combination of Knudsen and molecular diffusion, have milder temperature dependence.

Figure 12a shows the influence of the concentration of $\mathrm{CO}_{2}$ in the feed on the $\mathrm{CO}_{2} / \mathrm{N}_{2}$ separation factor calculated by the simulations of cases 1,2 , and 3 . It is interesting to observe that IAS predicts an increase in the $\mathrm{CO}_{2} / \mathrm{N}_{2}$ separation factor with the $\mathrm{CO}_{2}$ concentration in the feed, while the separation factor calculated using only the single component data follows the opposite trend. This is because the pure component model overestimates the amount of $\mathrm{N}_{2}$ coadsorbed with $\mathrm{CO}_{2}$, and the overestimation grows larger as the amount of $\mathrm{CO}_{2}$ adsorbed increases.

Figure $12 \mathrm{~b}$ shows the influence of temperature on the $\mathrm{CO}_{2} /$ $\mathrm{N}_{2}$ separation factor (cases 2, 4, and 5). Both simulations predict a decrease in the separation factor with temperature; however, the temperature dependence is much more pronounced when the separation factor is calculated using IAS data. This is because the difference between the amount of $\mathrm{N}_{2}$ calculated by IAS and that calculated by the pure component model drops significantly as temperature increases. On the other hand, the difference observed between the amounts of $\mathrm{CO}_{2}$ adsorbed calculated by both methods decreases only slightly.

\section{CONCLUSIONS}

The equilibrium of adsorption of pure $\mathrm{N}_{2}$ and $\mathrm{CO}_{2}$ over a microporous biochar with a narrow pore size distribution was evaluated through static measurements in a manometric device. The equilibrium shows the expected trend: the maximum adsorption capacity is higher for $\mathrm{CO}_{2}$ than for $\mathrm{N}_{2}$ and so is the isosteric heat of adsorption, with average values of $29 \mathrm{~kJ} \mathrm{~mol}^{-1}$ for $\mathrm{CO}_{2}$ and $20 \mathrm{~kJ} \mathrm{~mol}^{-1}$ for $\mathrm{N}_{2}$.

The influence of the feed composition on the adsorption behavior was evaluated from the kinetic and thermodynamic points of view carrying out dynamic breakthrough experiments in a fixed-bed adsorption unit with 8, 14, and 30\% $\mathrm{CO}_{2}$ (balance $\mathrm{N}_{2}$ ) at room temperature (cases 1, 2, and 3, respectively). The effect of temperature was evaluated for a feed gas containing $14 \% \quad \mathrm{CO}_{2}$ (balance $\mathrm{N}_{2}$ ) carrying out breakthrough experiments at 23,50 , and $70{ }^{\circ} \mathrm{C}$ (cases 2, 4, and 5 , respectively). The results confirm that $\mathrm{CO}_{2}$ is preferentially adsorbed over $\mathrm{N}_{2}$, and that it is possible to separate $\mathrm{CO}_{2}$ from
$\mathrm{N}_{2}$ in the wide variety of postcombustion scenarios evaluated using an inexpensive and environmentally friendly biochar. The thermal effects associated with the adsorption of $\mathrm{CO}_{2}$ are rather small, with the maximum temperature shift $\left(9^{\circ} \mathrm{C}\right)$ observed for the breakthrough curve carried with $30 \% \quad \mathrm{CO}_{2}$ at room temperature, in good agreement with the moderate values of the isosteric heat of adsorption of $\mathrm{CO}_{2}$ estimated from the pure component adsorption data.

The breakthrough experiments were simulated using Aspen Adsorption V8.0 using a dynamic fixed-bed gas adsorption model. Only the value of the effective diffusivity was fitted to avoid coupling effects between mass and heat transfer. According to the observed dependence of the effective diffusivity with temperature, $\mathrm{CO}_{2}$ adsorption seems to be controlled by surface diffusion, with an activation energy of approximately $36 \mathrm{~kJ} \mathrm{~mol}^{-1}$. The Toth equation provides a satisfactory description of the equilibrium of adsorption of the pure components as a continuous function of pressure and temperature that can be implemented in the mathematical model of the adsorption process. IAS theory was used to predict the equilibrium of adsorption of the binary $\mathrm{CO}_{2} / \mathrm{N}_{2}$ mixtures based on the pure components adsorption model (Toth equation). IAS-based simulation provides a better description of the experimental results compared to the simulations based solely on the equilibrium of adsorption of the pure components: on average, the error between the amounts of $\mathrm{CO}_{2}$ adsorbed calculated from the experimental data and those calculated by simulation is $3 \%$ for the IAS-based simulation, and $10 \%$ for the simulations based directly on the pure components adsorption models. Due to the preferential adsorption of $\mathrm{CO}_{2}$ over $\mathrm{N}_{2}$, the IAS theory predicts only a slight reduction (between -4 and $-11 \%$ in the conditions evaluated) in the adsorption capacity of $\mathrm{CO}_{2}$ in the presence of large amounts of $\mathrm{N}_{2}\left(70-92 \% \mathrm{~N}_{2}\right)$ but a drastic reduction in the adsorption capacity of $\mathrm{N}_{2}$ (weak adsorbate) in the presence of $\mathrm{CO}_{2}$ (up to $-76 \%$ for a mixture with $30 \% \mathrm{CO}_{2}$ at room temperature). Therefore, if competitive adsorption is not considered, the largest error is committed in the amount of $\mathrm{N}_{2}$ coadsorbed with $\mathrm{CO}_{2}$. The $\mathrm{CO}_{2}$ over $\mathrm{N}_{2}$ separation factor calculated by IAS increases as the partial pressure of $\mathrm{CO}_{2}$ in the gas phase increases, with values between 40 and 47 in the concentration range between 8 and $30 \%$ of $\mathrm{CO}_{2}$ at room temperature, and decreases with increasing temperature for a 
given concentration of $\mathrm{CO}_{2}$ down to a value of 24 at $70{ }^{\circ} \mathrm{C}$ for a $14 \%$ of $\mathrm{CO}_{2}$.

The dynamic fixed-bed gas adsorption model that makes use of IAS theory to simulate the competitive adsorption equilibrium of binary mixtures of $\mathrm{CO}_{2}$ and $\mathrm{N}_{2}$ has been validated with experimental breakthrough data in a wide range of operating conditions in terms of temperature $\left(23-70{ }^{\circ} \mathrm{C}\right)$ and feed composition $\left(8-30 \% \mathrm{CO}_{2}\right)$. This model reproduced satisfactorily not only the composition of the effluent during the breakthrough experiments but also its mass flow rate and the temperature history inside the adsorber. The gathered information will be used to extend the validity of the model to predict the kinetic and thermodynamic adsorption behavior of ternary mixtures of $\mathrm{N}_{2}, \mathrm{CO}_{2}$, and $\mathrm{H}_{2} \mathrm{O}$ in part 2, as a previous step to the use of the model for the design of a postcombustion $\mathrm{CO}_{2}$ capture process.

\section{ASSOCIATED CONTENT}

\section{S Supporting Information}

The Supporting Information is available free of charge on the ACS Publications website at DOI: 10.1021/acs.iecr.5b04856.

Adsorption isotherm of $\mathrm{N}_{2}$ at $-196{ }^{\circ} \mathrm{C}$ of the microporous biochar used as an adsorbent in the present work, summary of the equations, initial conditions, and nomenclature of the dynamic fixed-bed adsorption model used to run the simulations of the breakthrough experiments (PDF)

\section{AUTHOR INFORMATION}

\section{Corresponding Author}

*E-mail: cpevida@incar.csic.es.

\section{Author Contributions}

The manuscript was written through contributions of all authors. All authors have given approval to the final version of the manuscript.

\section{Funding}

HiPerCap Project (FP7).

\section{Notes}

The authors declare no competing financial interest.

\section{ACKNOWLEDGMENTS}

Work was carried out with financial support from the HiPerCap Project of the European Union 7th Framework Programme FP7 (2007-2013; Grant Agreement number: 60855). M.G.P. acknowledges funding from the CSIC (JAE-Doc program cofinanced by the European Social Fund). N.Q. acknowledges funding from the Government of the Principado de Asturias (Severo Ochoa Program). The authors also appreciate the support from the technical consultants of AspenTechnology Inc., M.M. and E.L.

\section{ABBREVIATIONS}

$\mathrm{ECV}=$ total Extra-Column Volume

GAC $=$ Granular Activated Carbon

IAS = Ideal Adsorption Solution

LDF = Linear Driving Force approximation

MSE $=$ Mean Squared Error

$\mu \mathrm{GC}=$ micro Gas Chromatograph

STP $=$ Standard Temperature and Pressure $\left(0{ }^{\circ} \mathrm{C}\right.$ and 0.1 $\mathrm{MPa}$ )

\section{Nomenclature}

$b_{k}=$ affinity constant of component $k\left(\mathrm{kPa}^{-1}\right)$

$b_{0, k}=$ affinity constant of component $k$ at the reference temperature $\left(\mathrm{kPa}^{-1}\right)$

$D_{\mathrm{e}, k}=$ effective diffusivity of component $k\left(\mathrm{~m}^{2} \mathrm{~s}^{-1}\right)$

$D_{\mathrm{p}}=$ particle diameter $(\mathrm{mm})$

$f^{0}=$ equilibrium model for pure component adsorption

$F_{k}=$ molar flow rate of component $k\left(\mathrm{mmol} \mathrm{min}^{-1}\right)$

HTC = heat transfer coefficient between the gas and the adsorbent particles $\left(\mathrm{W} \mathrm{m}{ }^{-2} \mathrm{~K}^{-1}\right)$

$h_{\mathrm{w}}=$ heat transfer coefficient between the gas and the wall of the adsorber $\left(\mathrm{W} \mathrm{m}^{-2} \mathrm{~K}^{-1}\right)$

$H_{\mathrm{amb}}=$ heat transfer coefficient between the wall of the adsorber and the environment $\left(\mathrm{W} \mathrm{m}^{-2} \mathrm{~K}^{-1}\right)$

$\mathrm{MTC}_{k}=$ lumped mass transfer coefficient of component $k$ $\left(\mathrm{s}^{-1}\right)$

$n_{k}=$ adsorbed concentration of component $k\left(\mathrm{mmol} \mathrm{g}^{-1}\right)$

$n_{k}^{0}=$ adsorbed concentration of pure component $k$ at the hypothetical pressure $p_{k}^{0}: n_{k}^{0}=f^{0}\left(p_{k}^{0}\right)\left(\mathrm{mmol} \mathrm{g}^{-1}\right)$

$n_{\mathrm{s}, k}=$ saturation capacity of component $k\left(\mathrm{mmol} \mathrm{g}^{-1}\right)$

$n_{\mathrm{T}}=$ total adsorbed concentration $\left(\mathrm{mmol} \mathrm{g}^{-1}\right)$

$P=$ total pressure $(\mathrm{kPa})$

$p_{k}^{0}=$ hypothetical pressure of the pure component $k$ that gives the same spreading pressure $(\pi)$ on the surface as that of the mixture

$Q_{k}=$ parameter of the Toth model related with the heat of adsorption of component $k\left(\mathrm{~J} \mathrm{~mol}^{-1}\right)$

$Q_{\text {st }}=$ isosteric heat of adsorption $\left(\mathrm{J} \mathrm{mol}^{-1}\right)$

$R=$ universal constant of gases $\left(\mathrm{J} \mathrm{mol}^{-1} \mathrm{~K}^{-1}\right)$

$R_{\mathrm{p}}=$ particle radius $(\mathrm{m})$

$t=$ time $(\mathrm{min})$

$T=$ temperature $(\mathrm{K})$

$T_{0}=$ reference temperature $(\mathrm{K})$

$T_{\mathrm{amb}}=$ ambient temperature $(\mathrm{K})$

$T_{\mathrm{b}}=$ adsorber temperature at $4.7 \mathrm{~cm}$ from the feed end $(\mathrm{K})$

$V_{\mathrm{b}}=$ volume of the adsorbent bed $\left(\mathrm{m}^{3}\right)$

$x_{k}=$ molar fraction of component $k$ in the adsorbed phase

$y_{k}=$ molar fraction of component $k$ in the gas phase

$z=$ reduced spreading pressure

\section{Greek symbols}

$\varepsilon_{\mathrm{T}}=$ total porosity of the adsorbent bed

$\phi=$ surface potential

$\pi=$ spreading pressure

$\tau_{k}=$ heterogeneity parameter of Toth adsorption model for component $k$

\section{REFERENCES}

(1) Ruthven, D. M. Principles of Adsorption and Adsorption Processes; John Wiley and Sons: New York, 1984.

(2) Martín-Martínez, J. M.; Torregrosa-Maciá, R.; MittelmeijerHazeleger, M. C. Mechanisms of adsorption of $\mathrm{CO}_{2}$ in the micropores of activated anthracite. Fuel 1995, 74, 111-114.

(3) Vishnyakov, A.; Ravikovitch, P. I.; Neimark, A. V. Molecular level models for $\mathrm{CO}_{2}$ sorption in nanopores. Langmuir 1999, 15, 87368742.

(4) Plaza, M. G.; Pevida, C.; Arenillas, A.; Rubiera, F.; Pis, J. J. $\mathrm{CO}_{2}$ capture by adsorption with nitrogen enriched carbons. Fuel 2007, 86, 2204-2212.

(5) Plaza, M. G.; Pevida, C.; Martín, C. F.; Fermoso, J.; Pis, J. J.; Rubiera, F. Developing almond shell-derived activated carbons as $\mathrm{CO}_{2}$ adsorbents. Sep. Purif. Technol. 2010, 71, 102-106.

(6) Martín, C. F.; Plaza, M. G.; Pis, J. J.; Rubiera, F.; Pevida, C.; Centeno, T. A. On the limits of $\mathrm{CO}_{2}$ capture capacity of carbons. Sep. Purif. Technol. 2010, 74, 225-229. 
(7) Presser, V.; McDonough, J.; Yeon, S.-H.; Gogotsi, Y. Effect of pore size on carbon dioxide sorption by carbide derived carbon. Energy Environ. Sci. 2011, 4, 3059-3066.

(8) Plaza, M. G.; García, S.; Rubiera, F.; Pis, J. J.; Pevida, C. Evaluation of ammonia modified and conventionally activated biomass based carbons as $\mathrm{CO}_{2}$ adsorbents in postcombustion conditions. Sep. Purif. Technol. 2011, 80, 96-104.

(9) González, A. S.; Plaza, M. G.; Rubiera, F.; Pevida, C. Sustainable biomass-based carbon adsorbents for post-combustion $\mathrm{CO}_{2}$ capture. Chem. Eng. J. (Amsterdam, Neth.) 2013, 230, 456-465.

(10) Plaza, M. G.; González, A. S.; Pis, J. J.; Rubiera, F.; Pevida, C. Production of microporous biochars by single-step oxidation: Effect of activation conditions on $\mathrm{CO}_{2}$ capture. Appl. Energy 2014, 114, 551562.

(11) Plaza, M. G.; González, A. S.; Pevida, C.; Rubiera, F. Green coffee based $\mathrm{CO}_{2}$ adsorbent with high performance in postcombustion conditions. Fuel 2015, 140, 633-648.

(12) Plaza, M. G.; Durán, I.; Rubiera, F.; Pevida, C. $\mathrm{CO}_{2}$ adsorbent pellets produced from pine sawdust: Effect of coal tar pitch addition. Appl. Energy 2015, 144, 182-192.

(13) Sjostrom, S.; Krutka, H. Evaluation of solid sorbents as a retrofit technology for $\mathrm{CO}_{2}$ capture. Fuel 2010, 89, 1298-1306.

(14) Myers, A. L.; Prausnitz, J. M. Thermodynamics of mixed-gas adsorption. AIChE J. 1965, 11, 121-127.

(15) Do, D. D. Adsorption Analysis: Equilibria and Kinetics; Imperial College Press: Singapore, 1998.

(16) IPCC Special Report on Carbon Dioxide Capture and Storage;

IPCC: Cambridge, United Kingdom; New York, 2005; p 442.

(17) Plaza, M. G.; González, A. S.; Pevida, C.; Rubiera, F. Influence of water vapor on $\mathrm{CO}_{2}$ adsorption using a biomass-based carbon. Ind. Eng. Chem. Res. 2014, 53, 15488-15499.

(18) Plaza, M. G.; Pevida, C.; Arias, B.; Fermoso, J.; Casal, M. D.; Martín, C. F.; Rubiera, F.; Pis, J. J. Development of low-cost biomassbased adsorbents for postcombustion $\mathrm{CO}_{2}$ capture. Fuel 2009, 88, 2442-2447.

(19) Dubinin, M. M.; Stoeckli, H. F. Homogeneous and heterogeneous micropore structures in carbonaceous adsorbents. J. Colloid Interface Sci. 1980, 75, 34-42.

(20) Dubinin, M. M. Fundamentals of the theory of adsorption in micropores of carbon adsorbents: Characteristics of their adsorption properties and microporous structures. Carbon 1989, 27, 457-467.

(21) Stoeckli, F.; Ballerini, L. Evolution of microporosity during activation of carbon. Fuel 1991, 70, 557-559.

(22) Plaza, M. G.; González, A. S.; Rubiera, F.; Pevida, C. Water vapour adsorption by a coffee-based microporous carbon: effect on $\mathrm{CO}_{2}$ capture. J. Chem. Technol. Biotechnol. 2015, 90, 1592-1600.

(23) Plaza, M. G.; González, A. S.; Rubiera, F.; Pevida, C. Evaluation of Microporous Biochars Produced by Single-step Oxidation for Postcombustion $\mathrm{CO}_{2}$ Capture under Humid Conditions. Energy Procedia 2014, 63, 693-702.

(24) Joss, L.; Mazzotti, M. Modeling the extra-column volume in a small column setup for bulk gas adsorption. Adsorption 2012, 18, 381393.

(25) Aspen Adsorption V8.0 guide; AspenTech: Bedford, MA, 2012.

(26) Fairbanks, D. F.; Wilke, C. R. Diffusion Coefficients in Multicomponent Gas Mixtures. Ind. Eng. Chem. 1950, 42, 471-475.

(27) Bird, R. B.; Stewart, W. E.; Lightfoot, E. N. Transport Phenomena; John Wiley \& Sons: New York, 1960.

(28) Prakash, M. J.; Prasad, M.; Srinivasan, K. Modeling of thermal conductivity of charcoal-nitrogen adsorption beds. Carbon 2000, 38, 907-913.

(29) Al-Muhtaseb, S. A.; Ritter, J. A. A statistical mechanical perspective on the temperature dependence of the isosteric heat of adsorption and adsorbed phase heat capacity. J. Phys. Chem. B 1999, 103, 8104-8115.

(30) Wakao, N.; Kaguei, S. Heat and Mass Transfer in Packed Beds; Gordon and Breach, Science Publishers, Inc.: New York, 1982.

(31) Yagi, S.; Kunii, D. Studies on heat transfer near wall surface in packed beds. AIChE J. 1960, 6, 97-104.
(32) Sircar, S.; Cao, D. V. Heat of adsorption. Chem. Eng. Technol. 2002, 25, 945-948.

(33) Glueckauf, E. Theory of chromatography. Part 10.-Formulae for diffusion into spheres and their application to chromatography. Trans. Faraday Soc. 1955, 51, 1540-1551.

(34) Yang, R. T. Gas Separation by Adsorption Processes; Imperial College Press: London, 1987.

(35) Gilliland, E. R.; Baddour, R. F.; Perkinson, G. P.; Sladek, K. J. Diffusion on Surfaces. I. Effect of Concentration on the Diffusivity of Physically Adsorbed Gases. Ind. Eng. Chem. Fundam. 1974, 13, 95100.

(36) Yang, R. T. Adsorbents: Fundamentals and Applications; John Wiley and Sons, Inc.: Hoboken, NJ, 2003. 